\title{
Auditory Cortex Electrical Stimulation Suppresses Tinnitus in Rats
}

\author{
Jinsheng Zhang ${ }^{1,2}$, Yupeng Zhang ${ }^{1}$, And Xueguo Zhang ${ }^{1}$ \\ ${ }^{1}$ Laboratory of Auditory Prostheses Research, Department of Otolaryngology-Head and Neck Surgery, 5E-UHC, Wayne State \\ University School of Medicine, 4201 Saint Antoine, Detroit, MI 48201, USA \\ ${ }^{2}$ Department of Communication Sciences $\mathcal{E}$ Disorders, Wayne State University College of Liberal Arts E S Sciences, 60 Farnsworth \\ St, Detroit, MI 48202, USA
}

Received: 17 June 2010; Accepted: 21 October 2010; Online publication: 6 November 2010

\begin{abstract}
Recent clinical studies have demonstrated that auditory cortex electrical stimulation (ACES) has yielded promising results in the suppression of patients' tinnitus. However, the large variability in the efficacy of ACES-induced suppression across individuals has hindered its development into a reliable therapy. Due to ethical reasons, many issues cannot be comprehensively addressed in patients. In order to search for effective stimulation targets and identify optimal stimulation strategies, we have developed the first rat model to test for the suppression of behavioral evidence of tone-induced tinnitus through ACES. Our behavioral results demonstrated that electrical stimulation of all channels (frequency bands) in the auditory cortex significantly suppressed behavioral evidence of tinnitus and enhanced hearing detection at the central level. Such suppression of tinnitus and enhancement of hearing detection were respectively demonstrated by a reversal of tone exposure compromised gap detection at $10-12,14-16$, and $26-28 \mathrm{kHz}$ and compromised prepulse inhibition at 10-12 and 26-28 kHz. On the contrary, ACES did not induce behavioral changes in animals that did not manifest any behavioral evidence of tinnitus and compromised hearing detection following the same tone exposure. The results point out that tinnitus may be more related to compromised central auditory processing
\end{abstract}

Correspondence to: Jinsheng Zhang · Laboratory of Auditory Prostheses Research, Department of Otolaryngology-Head and Neck Surgery, 5E-UHC - Wayne State University School of Medicine · 4201 Saint Antoine, Detroit, MI 48201, USA. Telephone: +1-313-5770066; fax: +1-313-5776318; email: jinzhang@med.wayne.edu than hearing loss at the peripheral level. The ACESinduced suppression of behavioral evidence of tinnitus may involve restoration of abnormal central auditory processing.

Keywords: tinnitus suppression, auditory cortex electrical stimulation, brain stimulation, acoustic startle reflex, gap detection, neuromodulation

Abbreviations: ABR - Acoustically evoked auditory brainstem responses; AC - Auditory cortex; ACES Auditory cortex electrical stimulation; BBN - Broad band noise; CF-Characteristic frequency; FTCFrequency tuning curve; PPI - Prepulse inhibition

\section{INTRODUCTION}

Tinnitus, ringing in the ears or head without external sound presence, is a prevalent problem, with $10-15 \%$ adults experiencing it continuously (Axelsson and Ringdahl 1989). Tinnitus can impact activities of daily living by producing anxiety, annoyance, irritability, disturbed sleep patterns, and depression (Tyler 1993; McKenna 2000; Dobie 2003). A variety of strategies have been tried for clinical management of tinnitus, with variable results. Recent clinical studies have shown some promising results from stimulation of the auditory cortex (AC) through transcranial magnetic stimulation (TMS), transcranial direct current stimulation, or direct electrical stimulation (Howard 2004; De Ridder et al. 2004; Langguth et al. 2006; Fenoy et al. 2006; Fregni et al. 2006; De Ridder et al. 2006; Friedland et al. 2007; 
Ashton et al. 2007; De Ridder et al. 2007a, b). The transcranial direct current stimulation approach is new and its related studies are limited. When using TMS, an electromagnet placed on the scalp generates magnetic field pulses of 100-300 $\mu \mathrm{s}$ in duration and 1.5-2.0 $\mathrm{T}$ in strength. Depending on the stimulation sites and parameters, and the types of tinnitus, the efficacy of suppression differs greatly across individuals, and in some cases, patients' tinnitus become worse (De Ridder et al. 2005; Langguth et al. 2006; Folmer et al. 2006; Londero et al. 2006). The shortcomings of using TMS include nonspecific stimulation of a brain area that is larger than the AC (33-96 $\mathrm{cm}^{2}$; Jalinous 1991) and limited penetration into the brain tissue (Plewnia et al. 2003).

To obtain more focal stimulation, direct auditory cortex electrical stimulation (ACES) has been tried for the clinical treatment of tinnitus (Howard 2004; Fenoy et al. 2006; De Ridder et al. 2006, 2007a; Friedland et al. 2007; Seidman et al. 2008). ACES can be achieved through an epidural electrode array placed on the AC surface (De Ridder et al. 2006; Friedland et al. 2007). Clinicians of our research group have demonstrated that direct electrical stimulation of Heschl's gyrus with intraparenchymal electrodes suppresses tinnitus in some patients (Seidman et al. 2008). In addition, transient tinnitus reduction has been obtained when applying anodal transcranial direct current to the temporoparietal area through saline-soaked surface sponges (Fregni et al. 2006). Compared to TMS, ACES tends to yield longer suppressive effects. The suppression from ACES can last up to 10 months (De Ridder et al. 2004). In addition, ACES tends to yield a higher degree of suppression of pure tone tinnitus $(97 \%$ compared to $77 \%$ ) but less suppression of white noise tinnitus (24\% compared to 67\%; De Ridder et al. 2006). Although ACES showed promising results for the suppression of tinnitus, there is a large variability in the efficacy across patients, and tinnitus can sometimes become worse following ACES due to electrode interfacing with brain tissues. For ethical reasons, extensive testing to search for effective stimulation strategies cannot be directly conducted on human subjects. There is a need to develop an animal model of ACES to suppress tinnitus. The current study demonstrated that electrical stimulation of all channels (frequency bands) in the AC, which is one of our ongoing studies to test electrical stimulation of different brain regions using different parameters, induced the suppression of behavioral evidence of tone-induced tinnitus. The eventual goal of this line of research was to fully develop an animal model that helps identify optimal stimulation targets and parameters to suppress behavioral evidence of tinnitus and understand the mechanisms underlying ACES-induced suppression of tinnitus and to promote advanced clinical investigations through neuromodulation.

\section{METHODS}

\section{Animal subjects}

Animal subjects were Long-Evans rats $(n=22$, male, age $=60-70$ days) purchased from the Charles River Laboratories. Among them, six animals were not included in the study due to their poor startle reflex responses. The remaining 16 animals were toneexposed to induce tinnitus and surgically implanted in the AC. Among 16 animals, four animals were excluded because electrode arrays fell off. The remaining 12 animals were tone-exposed to induce tinnitus. Since tone or noise exposure does not induce tinnitus in all animals, the absence of tinnitus in some tone-exposed animals creates a similar situation to that sham noise exposure animals usually do not manifest behavioral evidence of tinnitus. Among 12 animals, nine animals developed tinnitus and were referred to as tinnitus ${ }^{(+)}$animals, and three animals did not develop tinnitus and were referred to as tinnitus ${ }^{(-)}$animals. ACES-induced effects on gap detection results were compared between tinnitus ${ }^{(+)}$and tinnitus ${ }^{(-)}$animals following the same tone exposure condition. Such a comparison was intended to eliminate or minimize the influence of tone-induced hearing loss on the testing results compared to using sham tone exposure animals which are subject to interference from the hearing loss factor.

The rationale of using rats is that they demonstrate a substantial range of complex natural auditoryevoked behavior and have recently been successfully used in behavioral testing for tinnitus (Turner et al. 2006; Yang et al. 2007). They are also increasingly used as models in neuroprosthetics research (Rousche et al. 2003; Otto et al. 2005a; Witte et al. 2007; Zhang and Zhang 2010). All experimental procedures in this study were in compliance with the guidelines of the Institutional Animal Care and Use Committee at Wayne State University.

\section{Behavioral screening of tinnitus and hearing detection (before tone exposure)}

Each animal was placed in a custom-made conditioning restrainer for 4 days $(2 \mathrm{~h} /$ day $)$. Conditioning training prior to experimentation was necessary so that each animal was able to remain comfortable in a restrainer during experimentation. During testing, the restrainer along with the animal was placed in a behavior chamber for gap detection and prepulse inhibition (PPI) testing while electrical stimulation was delivered through a connected multi-channel switching headstage.

A gap detection startle reflex procedure was performed using a behavioral testing system (Kinder 
Scientific, Poway, CA). In a testing chamber, a piezoelectric transducer was attached to the floor of the chamber to measure startle force in Newtons. Peak-tobaseline startle responses were acquired in real time using commercially available Startle Monitor software (Kinder Scientific). Prior to each testing session, calibration of test stimuli was performed using a Newton impulse calibrator and a sound pressure level meter. In the gap detection procedure, each rat was tested in the chamber with a continuous background noise. The noise consisted of $2,000-\mathrm{Hz}$ bandpass noise signals at $6-8,10-12,14-16$, and $26-28 \mathrm{kHz}$, and broadband noise (BBN, 2-30-kHz range) was delivered at $60 \mathrm{~dB}$ SPL. The frequency bands were selected based on our experience; they were used to serve as representative frequency bands to cover the possible frequencies of tinnitus and to efficiently test tinnitus behaviorally within a short period of time. BBN was chosen to detect tinnitus of broadband quality. The noise bursts of 50-ms duration were presented at $115 \mathrm{~dB}$ SPL through a second speaker. In normal hearing rats, the presence of a 40 -ms silent period (gap) before a startle stimulus served as a strong inhibitory signal to suppress the startle reflex ( $B$ and $B^{\prime}$ in Fig. 1). A variety of background sounds with different frequency components and intensities were tested in a given session. In rats with tinnitus, when the background sound was qualitatively similar to their tinnitus, they failed to hear the silent gap and their reflex was not inhibited as it should be ( $C$ and $C^{\prime}$ in Fig 1).

The background conditions consisted of 16 trials in total, eight startle only and eight trials where the startle was preceded by a silent gap. The ratio of responses between the gap and no gap conditions indicated how well the animal could hear the silent gap. Similar size responses in both conditions indicated that the rat could not detect the silent gap effectively. Significantly smaller responses during the gap trials than during the no-gap trials (startle-only) reflected that the animal could clearly perceive the silent gap ( $B, B^{\prime}$ and $D, D^{\prime}$ in Fig. 1). The ratio of gap detection response over startle-only response was used to evaluate tinnitus. A typical session consisted of a 2min waiting period followed by approximately 80 trials (five conditions $\times 16$ trials each) presented with a variable inter-trial interval of 17-23 s.

In addition to ABR measurement to determine animals' hearing thresholds (see below), their hearing detection at the central level was evaluated by measuring PPI responses. The procedure for PPI testing was similar to the gap detection procedure,
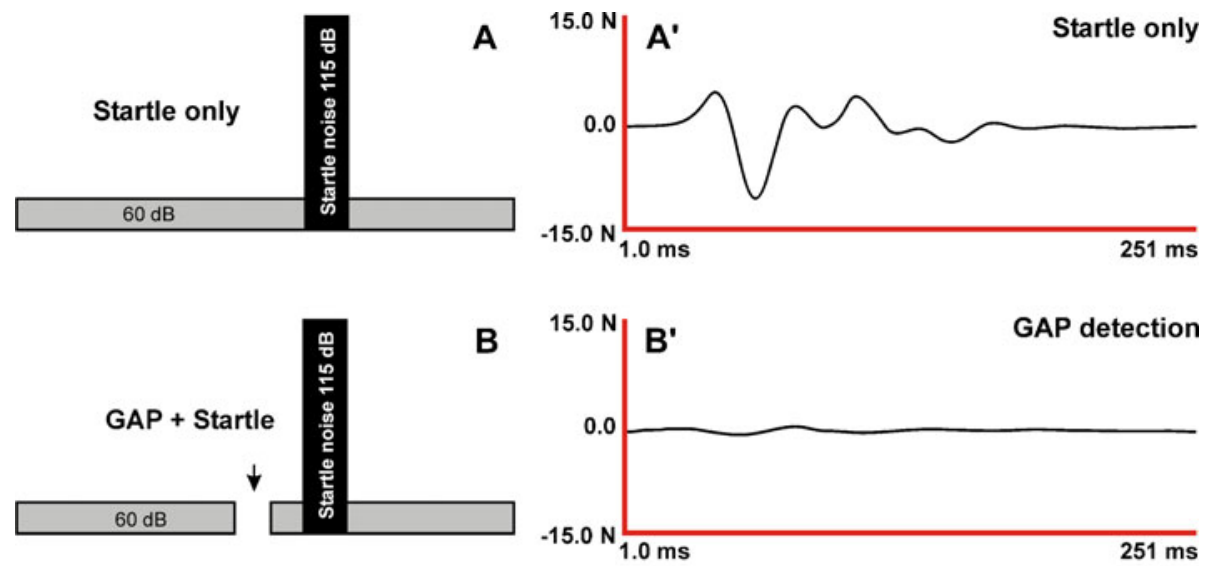

GAP detection
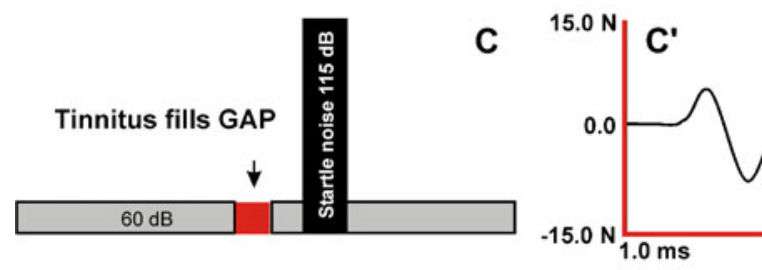

Tinnitus detection
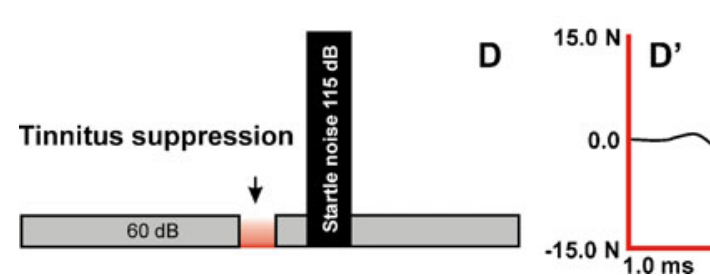

$-15.0 \mathrm{~N}$

$51 \mathrm{~ms}$
FIG. 1. Diagrams (left column) and screen shots from experiments (right column) showing: Startle stimulus alone $(A)$ yielded robust startle-only responses $\left(A^{\prime}\right)$; startle stimulus preceded by a $40-\mathrm{ms}$ silent gap $(B)$ suppressed startle responses, indicating detection of gap $\left(B^{\prime}\right)$; startle stimulus preceded by a gap that is filled with tinnitus signals $(C)$ yielded increased startle response, indicating gap detection was compromised $\left(C^{\prime}\right)$; decreased/suppressed tinnitus signals by ACES $(D)$ diminished startle responses, suggesting restoration of compromised gap detection $\left(D^{\prime}\right)$. Background noise was narrow band noise at $60 \mathrm{~dB}$ SPL and startle stimulus was broadband noise at $115 \mathrm{~dB}$ SPL. Startle responses were reflected in Newtons. 
except that no background noise was given. Instead, the gap was replaced with a $60-\mathrm{dB}$ SPL, $40-\mathrm{ms}$ prepulse starting at $100 \mathrm{~ms}$ before the 115-dB SPL startle sound. Each prepulse consisted of a $2-\mathrm{kHz}$ bandpass signal, shaped with a $0.1-\mathrm{ms}$ rise/fall time. The theory of PPI was that whenever an animal heard a prepulse sound of a certain frequency, the animal's startle reflex was suppressed compared to the startle-only response. On the contrary, if an animal lost hearing detection at a certain frequency, the magnitudes of startle responses with prepulses were not different from startle-only responses. The rat's PPI responses were tested at $6-8,10-12,14-16$, and $26-28 \mathrm{kHz}$ and BBN. The PPI testing conditions for each rat were identical, with duration of $50 \mathrm{~min}$ and a total of 80 trials.

\section{Testing ABR thresholds (before tone exposure)}

ABR thresholds to clicks and tones were obtained to evaluate the pre-tone exposure hearing condition. Briefly, following sound calibration and induction of anesthesia with a mixture of air $(0.4 \mathrm{l} / \mathrm{min})$ and isoflurane $(2-3 \%, v / v)$, three subdermal platinumcoated tungsten electrodes were inserted. The active electrode was inserted in the vertex, the return electrode was inserted below the left pinna, and the ground electrode was inserted into the contralateral temporal muscle. Clicks and tone bursts of $10-\mathrm{ms}$ duration at $8,12,16$, and $28 \mathrm{kHz}(0.1-\mathrm{ms}$ rise/fall time) were delivered to an electrostatic speaker. The stimuli were delivered from 80 to $5 \mathrm{~dB}$ SPL at 5 -dB steps in a descending order. The stimuli were generated by RX6 Multifunction Processor and SigGenRP software (TDT System 3). Calibration was achieved using SigCalRP ${ }^{\circledR}$ software. ABR signals were amplified, band- $(300 \mathrm{~Hz}-3 \mathrm{kHz})$ and notch-filtered $(60 \mathrm{~Hz})$, and averaged 300 times.

\section{Tone exposure to induce tinnitus}

During this procedure, animals were first sedated with a mixture of air $(0.4 \mathrm{l} / \mathrm{min})$ and isoflurane $(2-$ $3 \%, v / v)$. The right ear of the rat was then plugged with a Mack's ${ }^{\circledR}$ earplug and sealed with mineral oil. One animal was handled at a time by anesthetizing, plugging the right ear, and single-suturing the right pinna. Based on our empirical ABR data from comparing before and after tone exposure, such ear plugging and oil sealing generally prevents ABR threshold shift by 40-50 dB. For each exposure, four to five animals were placed in a cage. The dimension of the cage is $44.4 \mathrm{~cm}(L) \times 23 \mathrm{~cm}(W) \times$ $21.5 \mathrm{~cm}(H)$. The wall is made of plastic, with wood shavings as bedding. Exposure was started 15$30 \mathrm{~min}$ after all animals woke up from isoflurane.
The exposure tone was delivered to the animals through a loud speaker (TW67, Pyramid) that was placed right above the cage, thus exposing their left ears. The $10-\mathrm{kHz}$ exposure tone was generated through TDT hardware (RX6 Multifunction Processor) and software (OpenEx Suite), amplified (PV2600, Peavey Electronics Corporation), and delivered to the loud speaker. The sound level was monitored using a sound level meter (Bruel \& Kjar, BZ 7,100). A $10-\mathrm{kHz}$ sound of $120 \mathrm{~dB}$ SPL was delivered to the animal for $3 \mathrm{~h}$. Earplugs were taken out immediately after tone exposure. Following tone exposure, animals were returned to the animal quarter for at least $12 \mathrm{~h}$ before behavioral testing procedures.

It should be mentioned that using a $10-\mathrm{kHz}$ tone to expose animals was intended to generate data that can be used to compare with our previous work based on a 10-kHz tone exposure in both hamsters and rats (Zhang and Kaltenbach 1998; Kaltenbach et al. 2000; Zhang et al. 2006; Kaltenbach and Zhang 2007). Second, we intended to test if a pure tone exposure produces behavioral evidence of pure tone-type tinnitus compared to using narrow band noise by other investigators (Wang et al. 2009). As shown in the results below, pure tone exposure at $10 \mathrm{kHz}$ induced tinnitus at more than one frequency band, i.e., noise-type tinnitus.

In addition, exposing animals while awake was to conduct experiments in a way patients acquire their tinnitus from noise exposure while awake. This experimental procedure to expose animals while awake has previously been conducted by investigators in the field (Liberman and Gao 1995; Zheng et al. 1997).

\section{Behavioral testing for tinnitus and hearing detection (after tone exposure)}

Behavioral testing was performed to test for toneinduced tinnitus and track its development on a weekly basis for a period of about 4 weeks until behavioral evidence of tinnitus developed. In parallel, the PPI procedure was performed immediately after the gap detection procedure to measure and monitor changes in hearing detection.

\section{Testing ABR thresholds (after tone exposure)}

The same ABR procedure was repeated to examine the post-tone exposure hearing condition. The posttone exposure ABR data collection was completed over a period of 4 months.

\section{Surgical implantation in the AC}

Following identification of behavioral evidence of tinnitus, surgery was performed under aseptic con- 
ditions to implant a chronic stimulating electrode array in the right AC of each rat. Briefly, an animal was anesthetized with a mixture of air $(0.4 \mathrm{l} / \mathrm{min})$ and isoflurane $(2-3 \%, v / v)$. Its head was fixed to a stereotaxic device (Kopf model 1350). The animal's body temperature was maintained at $37^{\circ} \mathrm{C}$ by a thermostat-controlled blanket (Harvard Apparatus). A pair of custom-made hollow earbars was used to deliver sound. To expose the right $\mathrm{AC}$, a $3 \times 4-\mathrm{mm}$ craniotomy was performed at $4 \mathrm{~mm}$ lateral and $5 \mathrm{~mm}$ posterior to the bregma (Fig. 2). Three small stainless steel screws were installed around the opening and the dura mater was subsequently removed. The auditory core and belt regions were identified by stereotaxic coordinates, vascular landmarks (the anterior and posterior dorsoventral vessels, see Fig. 2A; Kelly and Sally 1988; Polley et al. 2007) and physiological response properties to tone and noise bursts (see below for more details). After taking photographs to record the surgical view, a $4 \times 4$, 16-channel microwire electrode array (Fig. 2B) was dipped in $3 \%$ Di-I solution (1,1'-dioctadecyl-3,3, $3^{\prime}, 3^{\prime}$-tetramethylindocarbocyanine perchlorate, Invitrogen) prepared with DMF to label the track of electrode insertions (Zhang and Zhang 2010). Then, the array was implanted into the AC and a silver wire for grounding connected to one of the stainless steel screws. The array was lowered $0.8-0.9 \mathrm{~mm}$ from the AC surface, which corresponds to layers 4-5. The 16-channel microwire arrays were provided by Clunbury Scientific. Each array consisted of 16 polyimide insulated platinum/iridium microwires that were arranged in four rows with four wires in each row (diameter= $50 \mu \mathrm{m}$; electrode spacing $=400 \mu \mathrm{m}$; row spacing $=$ $400 \mu \mathrm{m}$; impedance $=20-50 \mathrm{k} \Omega$ ). The array covered an area of about $1.2 \times 1.2 \mathrm{~mm}$ and was implanted in an area that contains both auditory core and belt regions.

During implantation, the AC core and belt regions were identified. The auditory core can be divided into the primary auditory cortex (AI), the anterior auditory field, the posterior auditory field, the ventral auditory field, and the suprarhinal auditory field (Polley et al. 2007). Most of the neurons in the auditory core usually respond well to pure tones and have sharp tuning properties (Fig. 2C) and shorter latencies. For example, the AI extends about $3.1 \mathrm{~mm}$ along the anteroposterior axis (2.7-5.8 $\mathrm{mm}$ posterior to bregma). The AI was defined by its short latency $(8-20 \mathrm{~ms})$ responses and its continuous tonotopy, with best frequencies increasing from posterior $(<1 \mathrm{kHz})$ to anterior $(>40 \mathrm{kHz}$; Kilgard and Merzenich 1999; Doron et al. 2002; Kilgard et al. 2007). The non-tonotopically organized auditory belt surrounds the auditory core. The belt consists of the posterodorsal, dorsal, and anterodorsal regions, ventral belt (ventral to $\mathrm{AI}$ ), and posterior belt (posterior to the posterior field; Rutkowski et al. 2003; Rutkowski and Weinberger 2005; Higgins et al. 2008). Neurons from the belt region were typically unresponsive to pure tones and very broadly tuned, often responding to over three octaves of frequencies or complex sounds of communicative and/or environmental significance. The
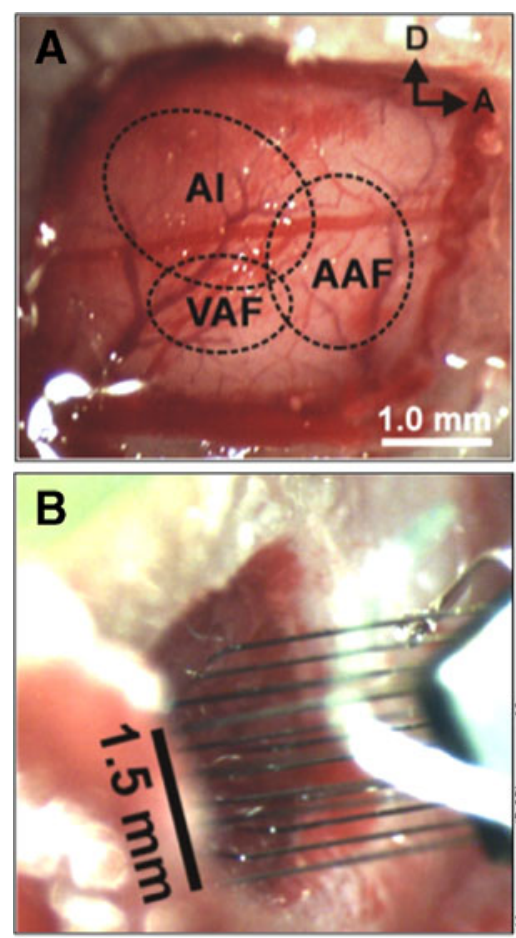
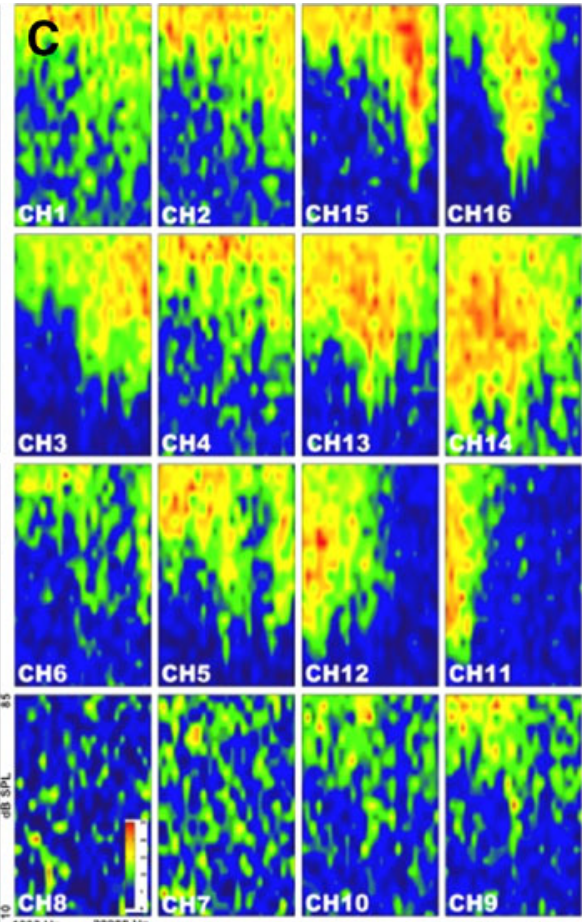

FIG. 2. An example showing chronic implantation of a $4 \times 4$ microwire electrode array in the rat $\mathrm{AC}$ and electrophysiological responses to acoustic stimulation. A AC areas before implantation. B Placement of a chronic microwire electrode array. C Frequency tuning curves were recorded and used to determine the frequency representations of the implanted electrodes in the AC. Responses in channels such as 1, 2, 3, 4, 5, 9, 11, 12, 13, 14, 15, and 16 were well or sharply tuned to tones, suggesting that these neurons are located in the core area of the AC. Responses in channels such as $6,7,8$, and 10 were less sensitive or broadly tuned to tones, suggesting that these neurons are probably near or located in the belt region. Scale bar for activity rate is on $\mathrm{CH} 8$. 
present study mainly focused on the general effects of ACES of all channels predominantly in the core region.

Frequency tuning curves (FTCs) were obtained in response to tone sweeps delivered to the left ear by an electrostatic speaker (Fig. 2C). The tone bursts were $50 \mathrm{~ms}$ in duration, at 500-ms intervals, with frequencies ranging from 4 to $44 \mathrm{kHz}$ and intensities in incremental steps of $2 \mathrm{~dB}$. Neural signals were preamplified and bandpass-filtered $(300-1,000 \mathrm{~Hz})$. The TDT preamplifier had a fixed gain (255X) with an input range of $\pm 4.5 \mathrm{mV}$ and a 16-bit signal resolution on the AD converters. The array was mounted on a TDT SH16 switching headstage and then connected to an auditory workstation (TDT System 3). The output was fed into a 40-bit neurophysiology base station (RX5 Pentusa, TDT) that was controlled by an OpenEx software suite.

After implantation and electrophysiological recordings, the microwire array was secured to the skull with dental acrylate. Each animal was allowed to recover from the surgery for at least 10 days before further experimentation.

Behavioral testing for ACES-induced suppression of tinnitus and restoration of compromised hearing detection in tinnitus ${ }^{(+)}$animals

Behavioral testing was first performed to retest the tone-induced behavioral evidence of tinnitus following surgical implantation. One day after robust evidence of tinnitus was identified, ACES was performed immediately. ACES was started $2 \mathrm{~min}$ prior to the initiation of behavioral testing sequence (i.e., gap plus startle stimulus). The electrical pulses were single charge-balanced, biphasic square-wave pulses (duration $=1.0 \mathrm{~ms}$ ) generated from TDT hardware (RX7 Microstimulator Base Station) and delivered at $50 \mu \mathrm{A}$ and $10 \mathrm{pps}$ through an optically isolated multichannel stimulator (MS16, TDT). The electrical pulses were delivered continuously at the fixed rate, independent of either gap or startle stimulus. All the electrodes in the array were stimulated simultaneously and with the same currents. To minimize current spread, electric current was delivered to adjacent electrodes in a bipolar stimulation mode. The suppressive effects of ACES on behavioral evidence of tinnitus were measured while the AC was stimulated electrically via the implanted microwire electrode array. Electrical stimulation was terminated immediately after completion of behavioral testing sequence. Since currently there is no established protocol in electrical stimulation to suppress tinnitus, the adopted low stimulation rate was based on previous reports that low-frequency rTMS tends to yield better suppression of tinnitus than high-frequency stimulation (Eichhammer et al. 2007; Langguth et al. 2008).

In addition, PPI responses were measured to determine whether ACES restored any compromised hearing detection at the central level as reflected by a reversal of compromised PPI responses.

\section{Behavioral testing in tinnitus ${ }^{(-)}$animals}

To verify that ACES-induced suppression of behavioral evidence of tinnitus was specific, we conducted control studies in three tinnitus ${ }^{(-)}$animals that did not develop tinnitus following the same tone exposure as used for tinnitus ${ }^{(+)}$animals. The rationale of using tinnitus ${ }^{(-)}$animals following the same tone exposure was to avoid or minimize the influence of tone-induced hearing loss on behavioral results. The same experimental procedures used for testing tinnitus $^{(+)}$animals were conducted on these tinnitus $^{(-)}$animals.

\section{Histological verification of electrode implantation}

After completion of all experimental procedures, each animal was deeply anesthetized with isoflurane and euthanized. The animal was perfused transcardially with $100 \mathrm{ml}$ saline followed by $300 \mathrm{ml} 4 \%$ paraformaldehyde in $0.1 \mathrm{M}$ phosphorate buffer ( $\mathrm{pH}$ 7.4). The acrylic head cap and underlying bone were isolated and removed. The brain was removed and post-fixed for $4-6 \mathrm{~h}$ in the same fixative and subsequently cryoprotected by immersion in 30\% sucrose in $0.1 \mathrm{M} \mathrm{PB}(\mathrm{pH} 7.4)$ at $4^{\circ} \mathrm{C}$ overnight. Brain sections of $100-\mu \mathrm{m}$ thickness were cut coronally with a sliding microtome (Microm HM 400 ) at $-20^{\circ} \mathrm{C}$, which was controlled by a BFS-MP Freezing Stage. The electrode tracks in the AC were verified under a Nikon PCM2000 confocal microscope with fluorescence capability.

\section{Data analysis}

The raw data in startle forces from individual animals were first averaged and plotted for gap detection, PPI, and startle-only responses before and after tone exposure as well as during ACES. To better appreciate the results and minimize the large variability in startle responses across individual animals and tests, ratio values were calculated and averaged from the raw data as described previously (Turner et al. 2006; Zhang and Zhang 2010). The ratio values were generated by dividing gap detection responses or PPI responses by their corresponding mean startleonly responses. 
To evaluate tone-induced behavioral evidence of tinnitus and deficits in hearing detection, gap detection and PPI responses at frequencies tested were compared with their corresponding startle-only responses using paired $t$ tests. A significant decrease in gap detection responses (presence of robust startle responses) indicated tinnitus ${ }^{(+)}$, and an insignificant decrease in gap detection responses (depression of startle responses) indicated tinnitus ${ }^{(-)}$. Similarly, a significant decrease in PPI responses (presence of robust startle responses) would indicate evidence of compromised hearing detection, and an insignificant decrease in PPI responses (depression of startle responses) would indicate no adverse effect on hearing detection. Data obtained from tinnitus ${ }^{(-)}$ animals were used to serve as controls to determine that ACES-induced suppression of tinnitus or restoration of the compromised hearing detection was specific.

To examine ACES-induced effects, comparisons were made among gap detection and PPI data that were acquired before tone exposure to induce tinnitus (PreExp), after tinnitus development but before ACES (PreStim), and during ACES (DurStim). Following ACES, a significant increase in gap detection responses (depression of startle responses) would suggest suppression of tinnitus. An insignificant increase in gap detection responses (presence of robust startle responses) would suggest no suppression of tinnitus. Similarly, following ACES, a significant increase in PPI responses (depression of startle responses) would suggest restoration of the hearing deficits, whereas an insignificant increase in PPI responses (presence of robust startle responses) would suggest no effect on the hearing deficits. For the above multiple comparisons, ANOVA was performed and post hoc Bonferroni method was used to adjust alpha values. Significant differences were judged by $p<0.05$.

To distinguish tone-induced tinnitus from hearing loss especially at the peripheral level, ABR data were compared between tinnitus ${ }^{(+)}$and tinnitus ${ }^{(-)}$animals using ANOVA with repeated measures. If tone exposure induced hearing loss in both tinnitus ${ }^{(+)}$and tinnitus $^{(-)}$animals, this would indicate that the toneinduced tinnitus may not necessarily be due to hearing loss itself and that ACES-induced suppression of tinnitus may be due to the direct modulation of neural correlates of tinnitus.

Finally, in order to verify that ACES-induced effects were caused by suppression of tinnitus rather than by the ACES acting directly as a potential startle suppressor itself, we tested the effects of ACES on startleonly responses. This test was performed by comparing the amplitudes of startle-only responses from before ACES (after tone exposure) with those from after ACES. Significance was examined using paired $t$ test.

\section{RESULTS}

Tonotopic representations of AC implants and histological verifications

Tonotopic representations of the implanted electrode array in the $\mathrm{AC}$ were determined by electrophysiological recordings of FTCs (Fig. 2C). Defining tonotopic representations in the current study was mainly to assure that the stimulation electrodes were implanted into the AC. Identification of tonotopic representations and core and belt regions are being used in an ongoing study to investigate the effects of stimulation of frequency loci and core and belt regions on ACES-induced tinnitus suppression.

In addition to electrophysiologically defining the locations of implanted electrodes, histological data were used to verify the locations of the implanted electrodes in the AC (data not shown). The histological results from all animals except for one showed that all the electrode arrays were implanted in the AC. The electrode tips were placed at layers $4-5$. The one animal without good histological results did not show visible fluorescent dye, probably due to improper dipping into the Di-I solution. Although unsuccessful dye labeling occurred in this animal, FTC recording was successful. Therefore, all of the available information confirmed that the currently employed ACES stimulated the AC.

\section{ACES suppressed tone-induced behavioral evidence of tinnitus and restored tone-induced hearing deficits}

To quantify behavioral data from tinnitus ${ }^{(+)}$and tinnitus $^{(-)}$animals following tone exposure and ACES, raw data (in Newtons) for gap detection, PPI, and startle-only responses in normal, tinnitus, and ACES conditions were calculated first (data not shown). To further process the data, ratio values of gap detection and PPI responses over their corresponding mean startle-only responses were plotted (Figures 3, 4, 5, and 6).

Our results demonstrated that animals with normal hearing were able to detect the short silent gaps or prepulses of different frequencies, and their startle reflex responses were depressed accordingly. Since gap detection and PPI startle reflex responses reflect bilateral integration, either gap signals or prepulses were detected by the contralateral unexposed right ears. About 4 weeks following tone exposure, compromised gap detection and PPI responses were identified, indicating that animals developed behavioral evidence of tinnitus and deficits in hearing detection.

The results also showed that chronic implantation of electrode arrays in the $\mathrm{AC}$ allowed the investigation 
ACES suppressed behavioral evidence of tinnitus: Gap detection data

A
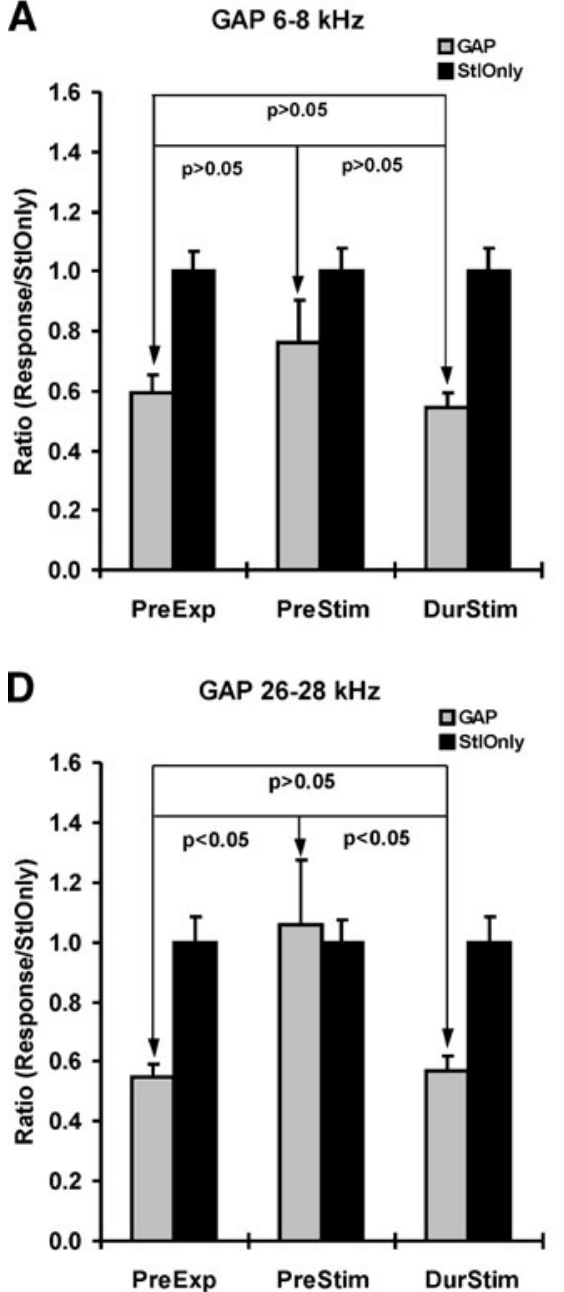

B

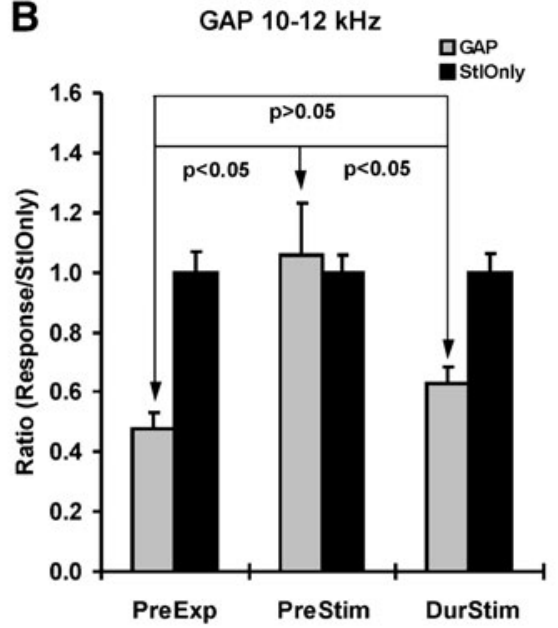

E

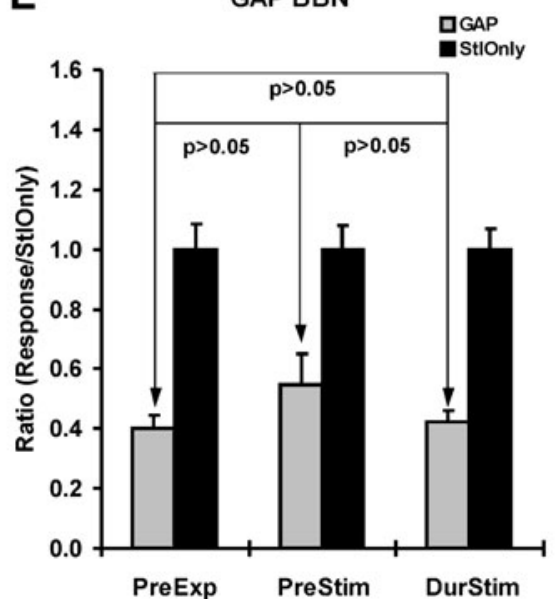

C $\quad \operatorname{GAP} 14-16 \mathrm{kHz}$

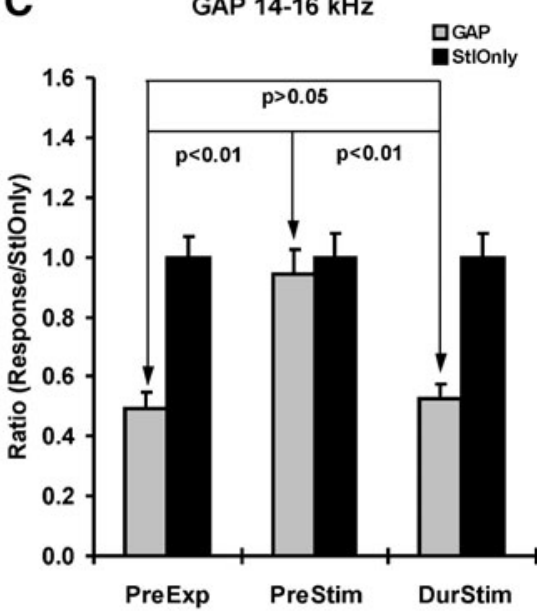

FIG. 3. Data showing tone-induced behavioral evidence of tinnitus and ACES-induced suppression of behavioral evidence of tinnitus. A-E Robust gap detection (PreStim condition) occurred at 6-8, 10$12,14-16$, and $26-28 \mathrm{kHz}$ and $\mathrm{BBN}$ prior to tone exposure, indicating no tinnitus development. B-D Comparison among PreExp, PreStim, and DurStim conditions demonstrated that following tone exposure, gap detection was significantly attenuated at 10-12, 14-

of ACES-induced suppression of tone-induced tinnitus and restoration of the induced deficits in hearing detection. During postoperative behavioral testing, we observed that both gap detection and PPI responses became significantly weak immediately following the recovery from surgical implantation. However, the behavioral evidence of tone-induced tinnitus and hearing deficits all recovered to the pre-implantation level within 1-2 weeks. This temporary depression of gap detection and PPI responses did not affect testing of ACES-induced effects. That is, ACES testing was performed 1-2 weeks after surgical implantation when significant tinnitus reappeared. We did observe fluctuations in the strength of tinnitus over time, which is consistent with other labs' results. However, ACES data collection only took place when robust
16 , and $26-28 \mathrm{kHz}$, indicating that tinnitus was developed at these frequencies. Comparison between PreExp and DurStim conditions demonstrated that ACES reversed the affected gap detection at these frequencies back to the normal state (PreExp condition). PreExp before tone exposure, PreStim after tone exposure but before ACES, DurStim during ACES to suppress tinnitus. Error bars represent the standard error of the mean.

tinnitus was seen. Below are the quantified results of ACES-induced effects on gap detection, PPI, and amplitudes of startle-only responses.

(a) ACES suppressed tone-induced behavioral evidence of tinnitus - gap detection data. To test for behavioral evidence of tone-induced tinnitus and the effects of ACES on behavioral evidence of tinnitus, gap detection data acquired PreExp, PreStim, and DurStim were plotted together according to the frequencies tested. Compared to startle-only responses, the results demonstrated robust suppression of behavioral evidence of tinnitus at certain frequencies in tinnitus ${ }^{(+)}$ animals. 
ACES restored hearing deficits in tinnitus(+) animals: PPI data

A
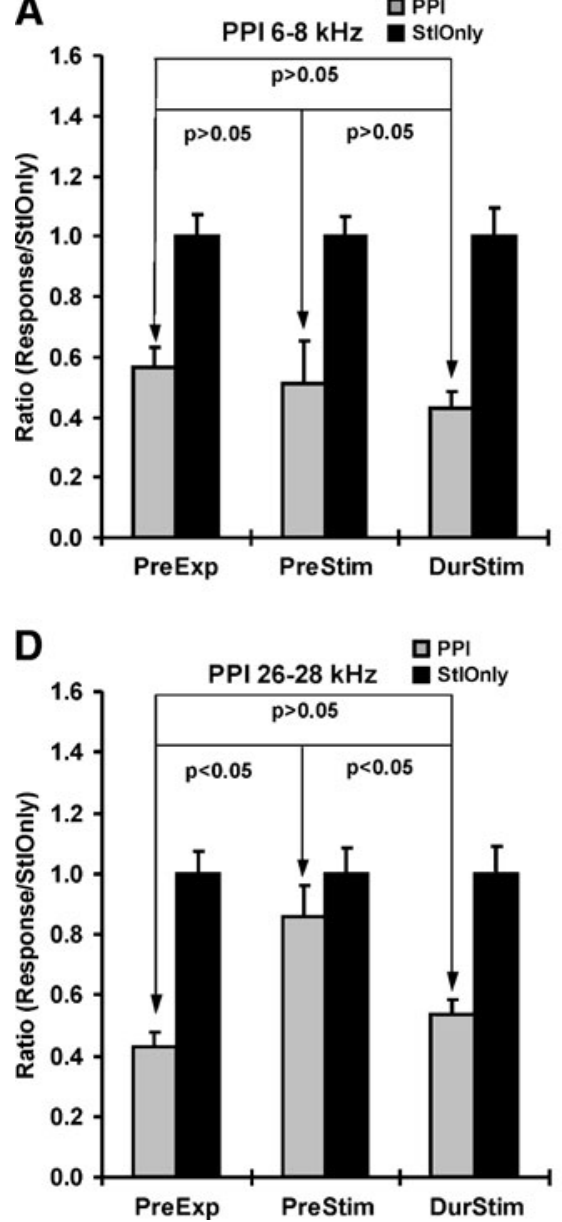

B
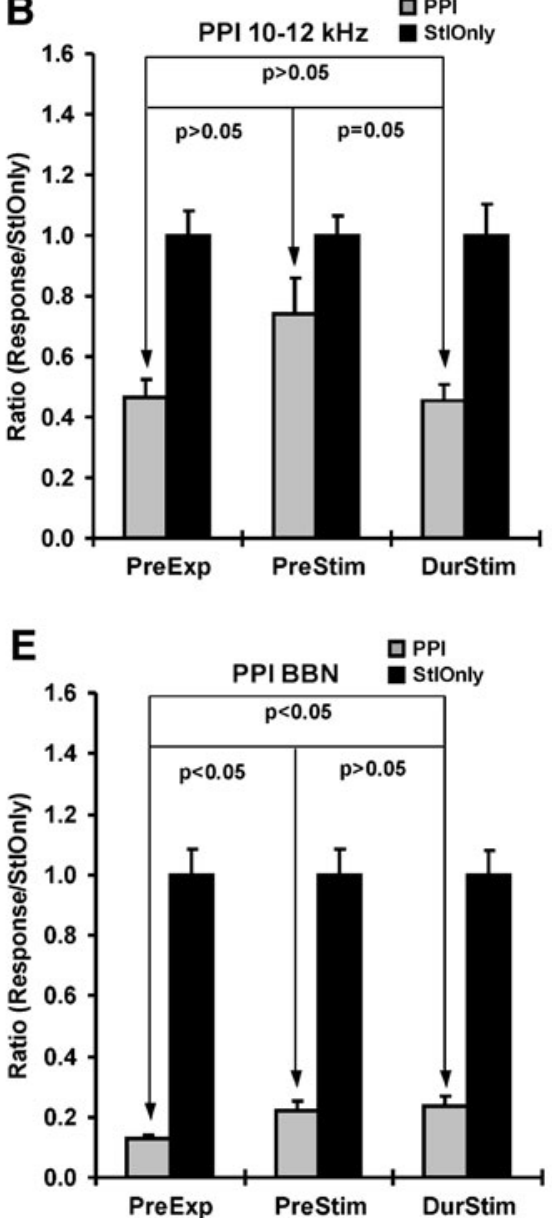

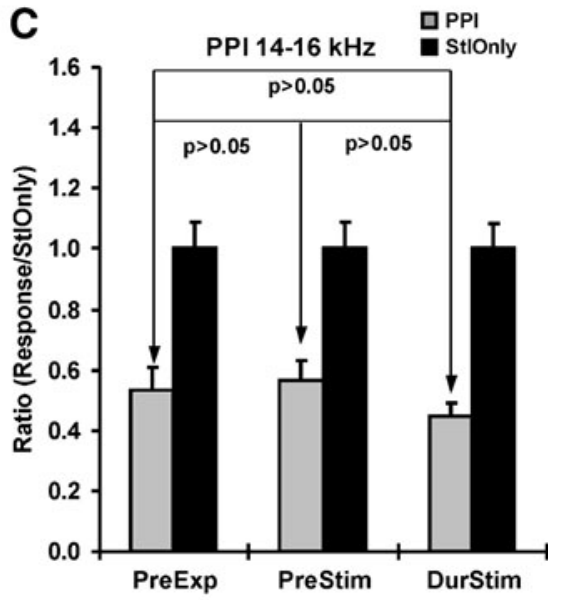

FIG. 4. Data showing tone-induced PPI deficit and ACES-induced reversal of the PPI deficit. Robust PPI responses (PreStim condition) were seen at all frequencies prior to tone exposure, indicating normal PPI responses (A-E). Comparison among PreExp, PreStim, and DurStim conditions demonstrated that following tone exposure, PPI was significantly attenuated at $26-28 \mathrm{kHz}$ and BBN. The data showed a tendency of tone-induced PPI attenuation at 10$12 \mathrm{kHz}$, although the statistics did not reach the significance ( $p=$ 0.07). In addition, although the statistics reached a significant level for PPI responses at BBN, the fact that PPI response was robust

Specifically, as shown in Figure 3A-E, nine animals manifested robust depression of startle responses at $6-8,10-12,14-16$, and $26-28 \mathrm{kHz}$ and BBN prior to tone exposure $(p<0.05$, paired $t$ tests $)$, indicating that these animals did not have tinnitus. Following tone exposure as compared to the PreExp condition, the gap detection was significantly decreased at $10-12(F=$ 7.7, $p<0.05), 14-16(F=16.5, p<0.01)$, and $26-28 \mathrm{kHz}$ $(F=5.0, p<0.05)$, respectively (ANOVA and post hoc Bonferroni test; Fig. 3B-D). This indicates that the induced behavioral evidence of tinnitus was robust at multiple frequencies even though the frequency of the exposure tone was $10 \mathrm{kHz}$. We did not observe significant evidence of tinnitus at $6-8 \mathrm{kHz}$ and $\mathrm{BBN}$, although there was a tendency of tinnitus develop- compared to startle-only response demonstrated that PPI responses were not significantly attenuated at $\mathrm{BBN}$, indicating a hearing detection. Following ACES, the attenuated PPI responses were significantly reversed at $26-28 \mathrm{kHz}$ and marginally reversed at 10 $12 \mathrm{kHz}(p=0.05)(\mathbf{B}, \mathbf{D})$. Comparison between PreExp and DurStim conditions demonstrated that ACES reversed the affected PPI to the normal state (PreExp condition) (B, D). PreExp before tone exposure, PreStim after tone exposure but before ACES, DurStim during ACES to suppress tinnitus. Error bars represent the standard error of the mean.

ment as suggested by a slight decrease in gap detection at $6-8 \mathrm{kHz}$ and $\mathrm{BBN}$ (Fig. 3A, E).

One day after demonstration of robust behavioral manifestations of tinnitus, electrical stimulation was delivered to the AC. As shown in Figure 3B-D, the decreased gap detection responses at the same frequencies were significantly reversed by ACES (1012 kHz: $F=7.7, p<0.05 ; 14-16 \mathrm{kHz}: F=16.5, p<0.01$; 26-28 kHz: $F=5.0, p<0.05$, ANOVA and post hoc Bonferroni tests). This indicated that the induced behavioral evidence of tinnitus was significantly suppressed by all-channel ACES. However, we did not observe significant changes in gap detection at 6$8 \mathrm{kHz}$ and BBN following ACES, although the slight tone-induced changes in gap detection were moder- 
ACES did not change gap detection in tinnitus(-) animals: Gap detection data

A
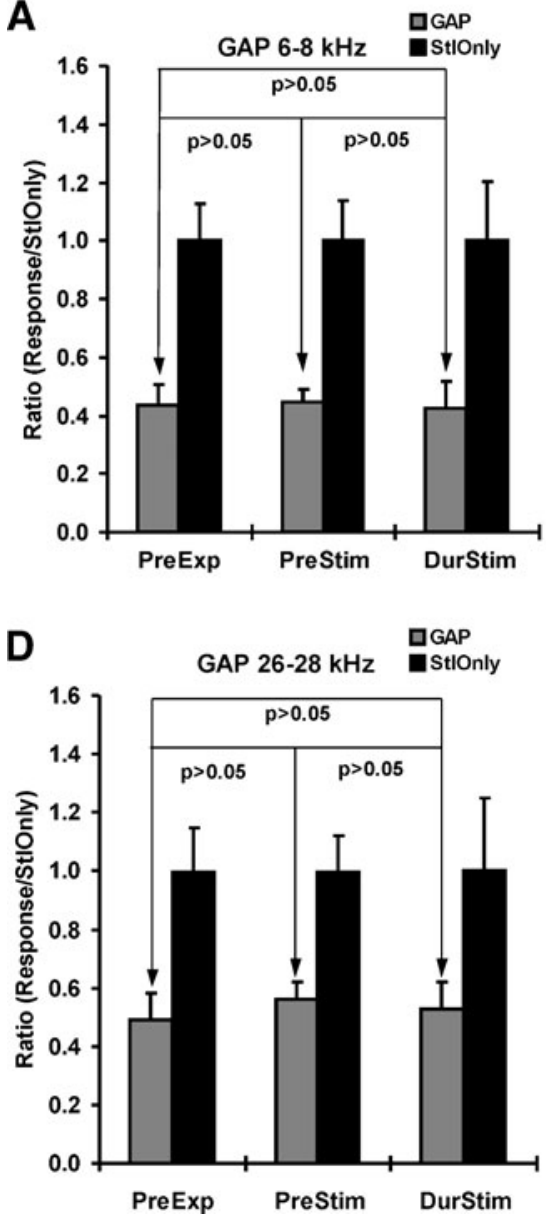

B

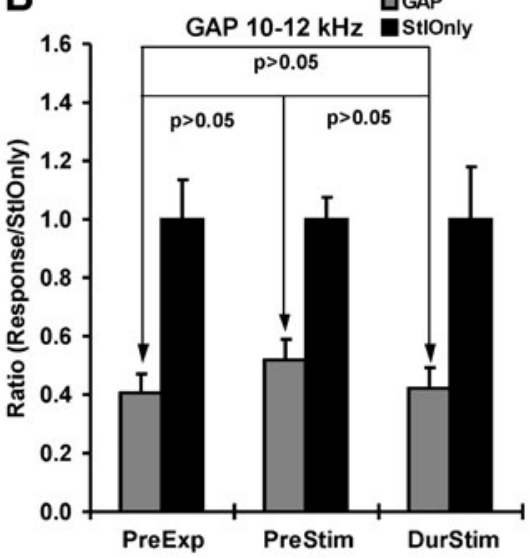

E

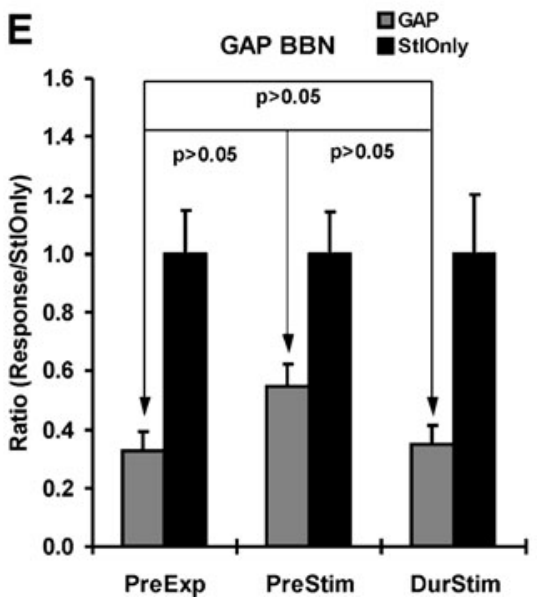

C

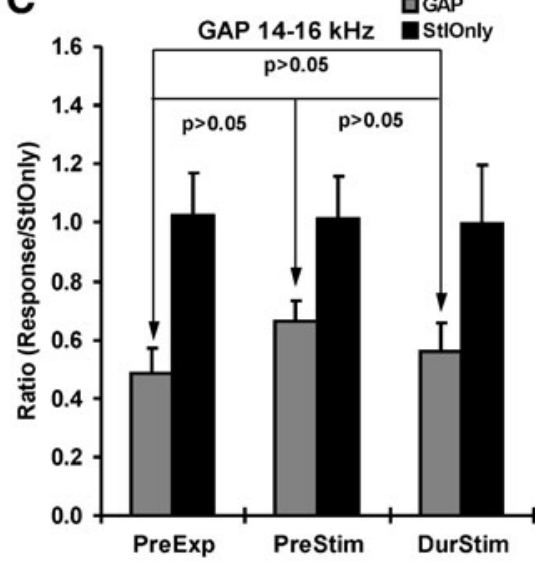

FIG. 5. Data from tinnitus ${ }^{(-)}$animals showing that tone exposure did not induce behavioral evidence of tinnitus (compromised gap detection) and ACES did not significantly affect the gap detection responses in tinnitus ${ }^{(-)}$animals. Note that significant

ately reversed by ACES (Fig. 3A, E). Finally, when comparing gap detection responses during ACES at each frequency with those from before tone exposure, we did not find any significant changes (Fig. 3A-E). This demonstrated that ACES completely reversed the compromised gap detection responses to the pre-tone exposure level. That is, the ACES completely suppressed the induced tinnitus at those frequencies.

(b) ACES restored tone-induced hearing deficitsPPI data. Similarly, to examine tone-induced impact on PPI responses and the effects of ACES on the compromised PPI responses, the PPI data acquired PreExp, PreStim, and DurStim were plotted together according to the frequencies tested. The results demonstrated that tone exposure decreased the hearing detection at certain frequencies and the decrease was also reversed by ACES.

Specifically, all nine animals demonstrated significant PPI-induced reductions of startle-only responses at 6- gap detection responses to $6-8,10-12,14-16$, and $26-28 \mathrm{kHz}$ and $\mathrm{BBN}$ sounds were found before and after tone exposure as well as during ACES (A-E). Error bars represent the standard error of the mean.

8, 10-12, 14-16, 26-28, and BBN $(p<0.05$, paired $t$ tests; Fig. 4A-E), suggesting sensitive hearing detection at these frequencies. Following tone exposure, the PPI responses at $26-28 \mathrm{kHz}(F=9.4, p<0.05)$ and BBN $(F=5.5, p<0.05)$ were significantly compromised (ANOVA and post hoc Bonferroni tests; Fig. 4D, E), whereas there were no significant changes in PPI responses at $6-8,10-12$, and $14-16 \mathrm{kHz}$ (Fig. 4A-C). Although the difference in PPI responses at 10$12 \mathrm{kHz}$ between PreExp and PreStim was not statistically significant $(p=0.07)$, the tone exposure tended to compromise hearing detection. In addition, although there was a significant change in PPI responses at BBN between PreExp and PreStim, the fact that PPI responses were robust at PreStim indicated that hearing detection was not significantly compromised. Following ACES, we observed that the compromised PPI responses at $26-28 \mathrm{kHz}$ were significantly reversed $(F=9.4, p<0.05$, ANOVA and post hoc Bonferroni tests; Fig. 4D). Similarly, the 
ACES did not change PPI responses in tinnitus(-) animals: PPI data
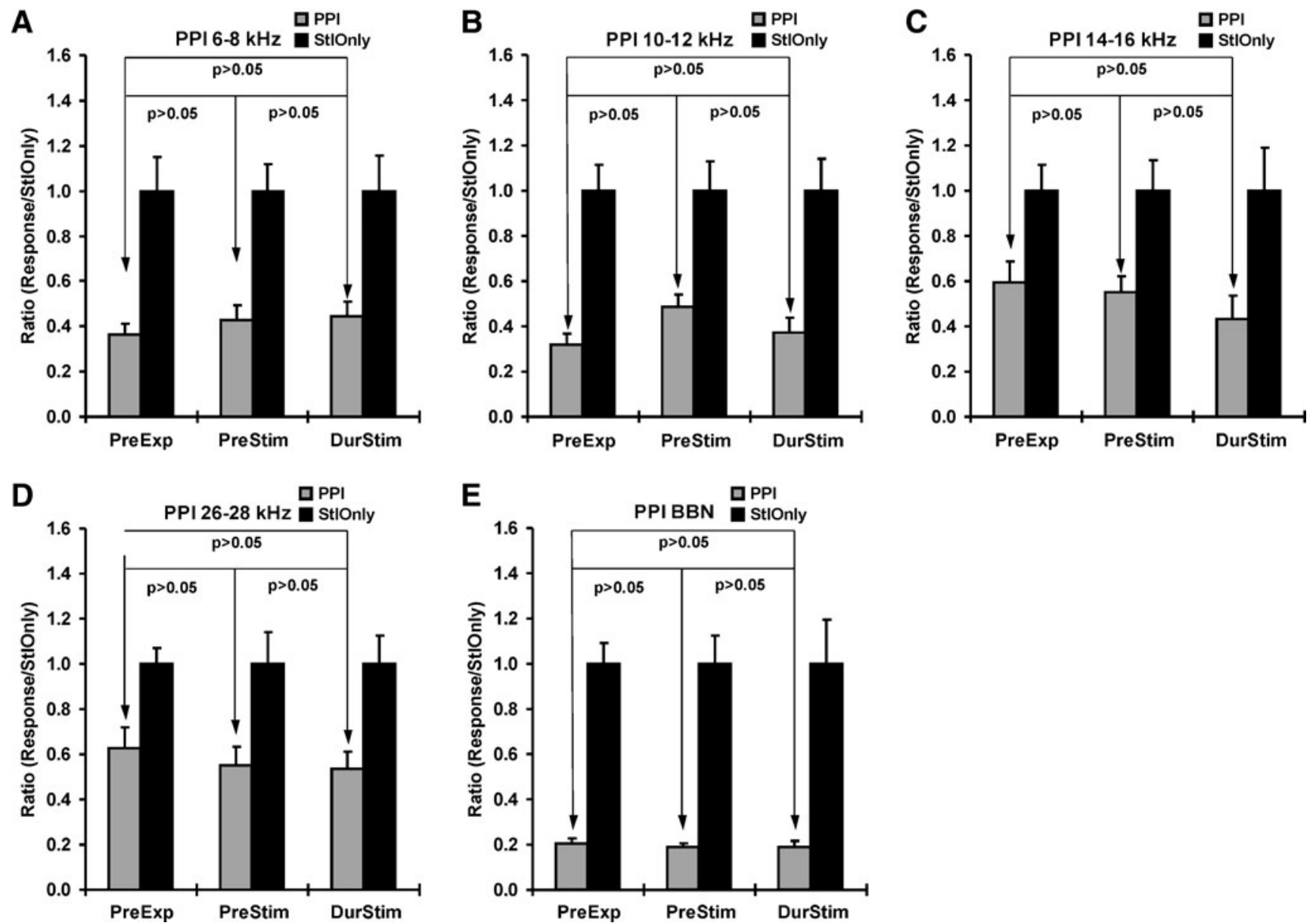

FIG. 6. Data from tinnitus ${ }^{(-)}$animals showing that both tone exposure and ACES did not affect PPI responses. Note that significant PPI responses (compared to startle-only responses) were seen before and after tone exposure as well as after ACES (A-E). Error bars represent the standard error of the mean.

moderately compromised PPI responses at $10-12 \mathrm{kHz}$ were also significantly reversed $(F=3.7, p=0.05$, ANOVA and post hoc Bonferroni tests; Fig. 4B). This demonstrates that ACES specifically reversed those affected PPI responses at both 10-12 and 26-28 kHz.

(c) ACES did not change gap detection and PPI responses in tinnitus ${ }^{(-)}$animals. Before tone exposure, the results from tinnitus ${ }^{(-)}$animals showed that gap detection responses were significantly robust compared to startle-only responses, indicating no evidence of tinnitus $(p<0.05$, paired $t$ tests; Fig. 5A-E). After pooling the data according to the frequencies tested, neither significant decreases in gap detection responses at 6-8, 10$12,14-16$, and $26-28 \mathrm{kHz}$ and $\mathrm{BBN}$ were induced by tone exposure, nor any significant changes in gap detection responses at these frequencies were affected by ACES (ANOVA and post hoc Bonferroni tests; Fig. 5A-E). This demonstrated that ACES did not have significant effects on gap detection in tinnitus ${ }^{(-)}$animals that did not develop tinnitus. This provided evidence that the currently used ACES had specific effects on the suppression of behavioral evidence of tinnitus in tinnitus ${ }^{(+)}$animals at certain frequencies.

Similarly, we found that the PPI responses at 6-8, 1012, 14-16, and 26-28 kHz and BBN were stable over the entire period of behavioral testing (Fig. 6A-E), indicating no significant changes before and after ACES. This also demonstrated that ACES did not significantly affect the behavioral manifestations of startle responses themselves in tinnitus ${ }^{(-)}$animals. This indicated that the currently used ACES had specific effects on the restoration of hearing deficits in tinnitus $^{(+)}$animals at certain frequencies.

(d) Effects of ACES on the amplitudes of startle-only responses in tinnitus ${ }^{(+)}$animals. Comparison of the amplitudes of startle-only responses before and after ACES in tinnitus ${ }^{(+)}$animals showed that ACES did not significantly decrease the amplitudes of startle-only responses at 6-8, 10-12, and 14-16 kHz and BBN (Fig. 7). However, ACES had restoration/enhancement effects on the amplitudes of startle-only responses at frequency 


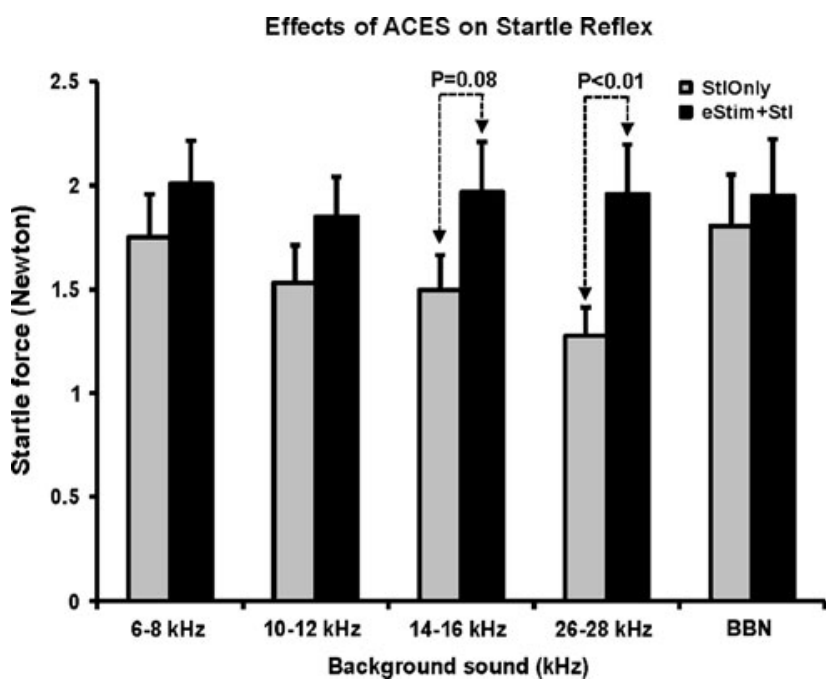

FIG. 7. Data from tinnitus ${ }^{(+)}$animals showing that ACES did not decrease the amplitudes of startle-only responses (background sounds without silent gaps) at lower frequency bands (6-8 and 10$12 \mathrm{kHz}$ ) and BBN. Instead, ACES tended to restore/enhance tone exposure-attenuated amplitudes of startle-only responses, especially for high-frequency bands at which gap detection was compromised and behavioral evidence of tinnitus was robust (compare gray and black bars). The restoration of the amplitudes of startle-only responses was significant at $26-28 \mathrm{kHz}$ and marginal at $14-16 \mathrm{kHz}$.

bands, especially the high-frequency bands (significant change at $26-28 \mathrm{kHz}$; moderate change at $14-16 \mathrm{kHz}$; slight change at $10-12 \mathrm{kHz}$, paired $t$ test). Interestingly, our tone exposure induced robust behavioral evidence of tinnitus at these frequency bands. These results demonstrated that ACES induced restoration/enhancement of tone exposure compromised startle-only responses, pointing out that ACES-induced suppression of behavioral evidence of tinnitus was caused by the suppression of tinnitus rather than by the ACES acting directly as a startle suppressor itself.

\section{ABR thresholds}

ABRs were recorded from six tinnitus ${ }^{(+)}$and three tinnitus $^{(-)}$animals. As expected, the ABR data demonstrated that the current tone exposure induced significant elevation in thresholds in both tinnitus ${ }^{(+)}$ and tinnitus ${ }^{(-)}$animals (Fig. 8).

Specifically, as shown in Figure 8A, the ABR data from tinnitus ${ }^{(+)}$animals demonstrated that compared to before tone exposure, the unilateral tone exposure used for tinnitus induction resulted in a significant elevation of hearing thresholds in the left ears when using clicks and tones at $8,12,16$, and $28 \mathrm{kHz}$ and BBN $(F=3.8, p<0.01)$. Compared to the left ears, the tone exposure induced significant elevation in ABR thresholds $(F=2.9, p<0.05)$. All the unexposed right
A

ABR threshold

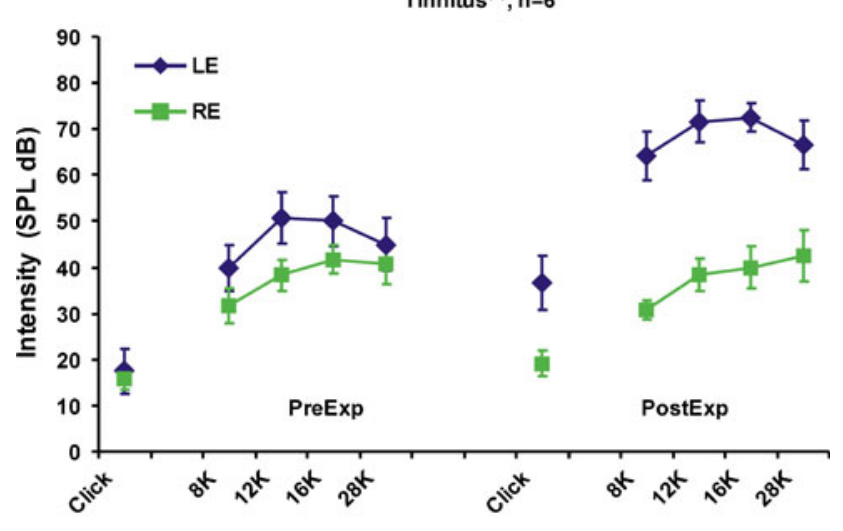

B

ABR threshold

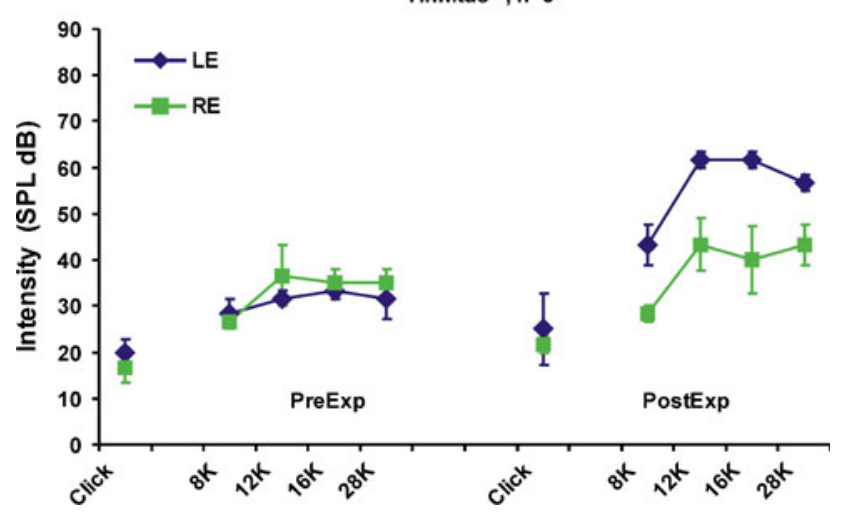

FIG. 8. Click- and tone-evoked ABR thresholds collected before and 4 months after tone exposure. The data showed that no significant difference in tone-induced ABR threshold shifts in the left ears (LES) was found between tinnitus ${ }^{(+)}$and tinnitus ${ }^{(-)}$animals. A ABR data from tinnitus $^{(+)}$animals showing that tone exposure induced significant hearing loss in the LE compared to pre-exposure data from the LE and compared to post-exposure data from the right ear $(R E)$. B Similar ABR data from tinnitus ${ }^{(-)}$animals showing that tone exposure induced significant hearing loss in the LE compared to pre-exposure data from the LE. One difference was that the hearing thresholds in tinnitus $^{(-)}$animals were not significantly affected using clicks and less affected at $8 \mathrm{kHz}$ compared to those in tinnitus $^{(+)}$animals. In both tinnitus ${ }^{(+)}$and tinnitus ${ }^{(-)}$animals, their intact right ears maintained relatively normal hearing. Error bars represent the standard error of the mean.

ears had normal hearing thresholds when comparing before and after tone exposure.

Similarly, as shown in Figure 8B, the ABR data from tinnitus $^{(-)}$animals also showed that their left ears had significant elevation in hearing thresholds when using tones of $8,12,16$, and $28 \mathrm{kHz}(F=5.4, p<0.05)$. There was no significant elevation in ABR thresholds when using clicks. This seemed to coincide with the relatively less effects on ABR thresholds at a lower frequency such as $8 \mathrm{kHz}$ (Fig. 8B). This may be due to a recovery in the apical region of the cochlea in those tinnitus $^{(-)}$animals. Their unexposed right ears did not manifest any significant elevation in hearing thresholds. 
When comparing the ABR data from the left ears between tinnitus ${ }^{(+)}$and tinnitus ${ }^{(-)}$animals, the results showed that there was no statistically significant difference in ABR threshold shifts in the left ears, although the tone-induced impact on left ears tended to be higher in tinnitus ${ }^{(+)}$than in tinnitus ${ }^{(-)}$animals (Fig. 8A, B). The non-significant difference in ABR threshold shifts in the exposed left ears between tinnitus $^{(+)}$and tinnitus ${ }^{(-)}$animals suggested that the impact of acoustic lesion on hearing threshold in both groups of animals may have been canceled out and that the tone-induced behavioral evidence of tinnitus as well as the ACES-induced suppression of tinnitus may represent the net effects on tinnitus.

\section{DISCUSSION}

\section{Summary of results}

To our knowledge, this is the first study to demonstrate that ACES suppresses behavioral evidence of tinnitus in a rat model. First, the induced suppression of tinnitus is due to the activation of the AC. This was supported by the electrophysiological data showing that FTCs were recorded from the implanted electrodes in the $\mathrm{AC}$ (Fig. 2) and by the histological data confirming that the electrode arrays were implanted into the AC.

Second, ACES did not decrease the amplitudes of startle-only responses at $6-8,10-12$, and $14-16 \mathrm{kHz}$ and BBN (Fig. 7), but tended to restore/enhance those at tone exposure-affected frequency bands that were associated with tinnitus. Additional evidence from our preliminary report presented at the 2010 ARO meeting (abstract no. 434) demonstrated that ACES-induced suppression of behavioral evidence of tinnitus lasted up to $48 \mathrm{~h}$ following the cessation of ACES. All the information lends support to our hypothesis that ACES specifically suppresses behavioral evidence of tinnitus rather than the ACES acting directly as a startle suppressor itself.

Third, ACES specifically suppressed tinnitus in tinnitus $^{(+)}$animals that also developed hearing loss in the left ears following unilateral tone exposure. This is in line with the literature that tinnitus is often accompanied by hearing loss (Komiya and Eggermont 2000; Ratnayake et al. 2009; Martines et al. 2010; Moore et al. 2010). However, the tone-induced tinnitus may still be separated from hearing loss since there is no significant difference in tone-induced ABR threshold shift in the left ears between tinnitus ${ }^{(+)}$and tinnitus $^{(-)}$animals (Fig. 8A, B), indicating that tone exposure causes hearing loss but not necessarily tinnitus in certain animals. On the other hand, the fact that ACES did not affect the behavioral data obtained from tinnitus ${ }^{(-)}$animals indicates that the ACES-induced suppression of behavioral evidence of tinnitus in tinnitus ${ }^{(+)}$animals is not necessarily due to any influence of hearing loss. That is, the currently induced tinnitus may be separated from the induced hearing loss, and the hearing loss may not necessarily affect the tone-induced tinnitus and ACES-induced suppression of tinnitus.

Complete separation of tinnitus from hearing loss might possibly be attained with different exposure conditions. It has recently been reported that a 17 $\mathrm{kHz}$ center octave-band noise at $116 \mathrm{~dB}$ SPL for $1 \mathrm{~h}$ immediately induced significant ABR threshold shift in rats, but tinnitus did not appear until 16 weeks after noise exposure, which was accompanied with a recovery of hearing threshold (Wang et al. 2009). In the current study, tinnitus did not appear until after about 4 weeks following exposure to a $10-\mathrm{kHz}$ tone at $120 \mathrm{~dB}$ SPL for $3 \mathrm{~h}$. The induced tinnitus persisted throughout the remaining testing period. However, the induced ABR threshold shift did not recover over a period of 4 months. Apparently, there is a need to develop a better set of sound exposure parameters with proper duration and intensity so that tinnitus develops more quickly and ABR threshold shift recovers sooner.

Fourth, we observed that there was a temporary depression for both gap detection and PPI responses immediately following the recovery from surgical implantation. The behavioral evidence of both toneinduced tinnitus and hearing deficits fully recovered to the pre-implantation level, which did not affect testing of ACES-induced effects. Such temporary depression of gap detection and PPI responses is probably related to surgical implantation. However, the underlying mechanisms as to how implantation of electrode arrays influences the brain functions are unclear and deserve further investigation.

Finally, although a $10-\mathrm{kHz}$ tone was used to produce damage, the induced hearing loss and tinnitus occurred at multiple frequencies. This is consistent with the occurrence of direct synaptic and trans-synaptic degenerations at multiple levels of the auditory system, triggering reorganization of tonotopic maps (Bilak et al. 1997; Morest et al. 1998; Syka 2002; Shore et al. 2008; Leake et al. 2008). The induced plastic changes along the auditory pathways may diverge to impact a broad tonotopic region. The fact that the currently used ACES may have significantly suppressed tinnitus at multiple frequencies indicates that all-channel ACES may be appropriate for treating tinnitus with multiple frequencies.

\section{ACES relieves tinnitus through improving central auditory processing}

We found that abnormal gap detection at 10-12, 1416 , and $26-28 \mathrm{kHz}$ and abnormal PPI responses at 
10-12 and 26-28 kHz occurred in tinnitus ${ }^{(+)}$animals even though the right ears had normal ABR thresholds. The compromised gap detection and PPI responses resulting from the acoustic lesion in the left ear might have occurred at the central level through binaural integration. Such compromised gap detection and PPI responses represent certain types of central auditory processing disorders that may have contributed to the measured behavioral evidence of tinnitus. If the compromised gap detection and PPI responses represent abnormal central auditory processing and plasticity underlying tinnitus, we hypothesize that the ACES-induced suppression of tinnitus may be achieved by enhancing detection of silent gaps and prepulses and hearing sensitivity at the central level, thus modulating brain plasticity. Alternatively, the ACES-induced suppression of tinnitus may result from signal augmentation or enhanced hearing sensitivity that might serve to mask tinnitus signals. This is in line with a notion that unmasking may cause tinnitus by unmasking of dormant synapses, diminishing of (surround) inhibition, lateral spread of neural activity, and development of hyperexcitability regions in the central nervous system (Bartels et al. 2007). The current data suggest that tinnitus could be managed by improving hearing thresholds or hearing sensitivity, at least at the central level.

The abnormal gap detection and PPI responses in tinnitus $^{(+)}$animals and ACES-induced improvement may represent plastic changes in central processing (Ison et al. 2002; Turner et al. 2006; Sun et al. 2009) and their neuromodulation, respectively. For example, there is evidence that PPI reflects fast, early-stage gating processing that can be modulated by higher order cognitive processes in both humans and rats (Bjornsson et al. 2006). Gap detection or PPI involves a complex neural network extending from multiple brainstem nuclei including the inferior colliculus (IC; Walton et al. 1997), superior colliculus, and pedunculopontine tegmental nucleus to higher order cortical areas (Campbell et al. 2007). It can be modulated by both attention and emotion. Several lines of evidence suggest that this early-stage gating is modulated by higher order cognitive processes (Braff et al. 2001; Swerdlow et al. 2001; Sobin et al. 2005; Bjornsson et al. 2006). A prepulse presented at short lead intervals reduces the perceived loudness of the probe stimulus, suggesting prepulse-mediated inhibition of auditory cortex processing (Perlstein et al. 1993). For instance, previous studies have reported prepulse-mediated gating of sensory thalamic input into the primary auditory projection area of the avian telencephalon (Schall et al. 1999). Bilateral AC lesions eliminate gap detection (Bowen et al. 2003) and unilateral AC lesions result in a significant decrease in the PPI (Clarkson et al. 2009), indicating the involvement of the AC. In addition, the circuitry mediating PPI receives direct axonal projections from forebrain structures such as the AC (Herbert et al. 1991), hippocampus and amygdala (Miller et al. 2010), and lateral globus pallidus (Takahashi et al. 2007), respectively. Furthermore, although no clear explanation as to why PPI responses at $10-12$ and $26-28 \mathrm{kHz}$ were compromised in tinnitus ${ }^{(+)}$animals, it is tempting to speculate that stronger effects from harmonic sounds related to the frequency $(10 \mathrm{kHz})$ of the exposure tone may have occurred. The ABR thresholds during ACES were not known since the current design did not allow us to collect ABR data while performing ACES. The hearing sensitivity was only derived from PPI measures.

Taken together, gap detection and PPI responses may measure auditory processing and the related plasticity at both brainstem and cortical levels, which may be modulated by activating corticofugal projections. The fact that ACES restores both gap detection and PPI responses in tinnitus ${ }^{(+)}$animals demonstrates that improving central auditory processing may help relieve tinnitus. That is, the mechanisms underlying tinnitus management may include direct modulation of neural correlates of tinnitus, possibly through ACESinduced neuromodulation or masking mechanisms resulting from improved central auditory processing.

\section{ACES suppresses tinnitus through top-down neuromodulation}

ACES may take a top-down approach to modulate neural correlates of tone-induced tinnitus through corticofugal pathways. The fact that gap detection and PPI involves complex neural network extending from multiple brainstem nuclei to higher order cortical areas (Campbell et al. 2007) and that startle-only responses involve cochlear nucleus, lateral lemniscus, and pontine reticular nucleus (Davis et al. 1982; Lee et al. 1996) points out that ACES-induced suppression of tinnitus (improved gap detection) (Fig. 3) and restoration/enhancement of the amplitudes of startleonly responses in tinnitus ${ }^{(+)}$animals (Fig. 7) may have different underlying neural mechanisms. Based on available knowledge (see discussions below), it is tempting to speculate that ACES-induced effects on gap detection and PPI responses may involve neuromodulation more at cortical than at brainstem levels, whereas ACES-induced effects on the amplitudes of startle-only responses may involve neuromodulation more at brainstem than cortical levels. However, these hypotheses need to be validated by further studies.

In addition, although electrophysiological data were not recorded from the same animals to correlate with behavioral data of tinnitus and its ACES modulation, recent results from our lab and others support 
the possibility that neuromodulation may have contributed to the ACES-induced suppression of tinnitus. For example, stimulation of the AC suppresses tinnitus in patients by reducing hyperexcitability in the AC (Londero et al. 2006; De Ridder et al. 2006), increasing intracortical inhibition (Langguth et al. 2007) and modulating the tonotopic map in the AC (Muhlnickel et al. 1998). Along the same line, our recent investigations showed that ACES can modulate spontaneous activity by inducing onset suppression, residual inhibition, and excitation in the dorsal cochlear nucleus (DCN) and IC (Zhang et al. 2008, 2010). The above neuromodulation is also based on other related reports that cortical stimulation can change the functional organization of the cortex (Schreiner and Cynader 1984; Maldonado and Gerstein 1996; Chowdhury and Suga 2000; Talwar and Gerstein 2001; Otto et al. 2005b) and produce widespread changes in regional synaptic activity within cortical and subcortical structures (Baumer et al. 2003; Li et al. 2004).

Finally, our recent studies showed that ACES induced a higher degree of suppression of neural activity in noise-exposed animals compared to controls (Zhang et al. 2008, 2010). The results are consistent with published information that somatosensory stimulation induces more inhibition in the DCN of noise-exposed animals than controls (Shore et al. 2008). This suggests that suppression of tinnitus results from rebalancing excitatory and inhibitory processes. The ACES-induced suppressive effects on spontaneous activity along the auditory axis may be one of the underlying mechanisms of ACES-induced suppression of tinnitus. Furthermore, we have recently found that ACES not only modulates neural activity within individual auditory brain structures but also adjusts neural information flow across auditory brain structures (Zhang et al. 2010). A further study is underway to validate the findings in tinnitus ${ }^{(+)}$ animals using multi-structure and multi-channel recordings and coherence analysis.

\section{Significance and future prospects}

The present study demonstrated that ACES yielded robust suppression of behavioral evidence of toneinduced tinnitus, which is in line with recent clinical reports (Howard 2004; Fenoy et al. 2006; De Ridder et al. 2006; Friedland et al. 2007; Seidman et al. 2008). Although knowledge obtained from animal studies may not be directly applied to clinical practice, information from animal studies may be extrapolated to promote advanced clinical investigations. Further animal studies are needed to investigate the lasting effects of ACES-induced suppression of tinnitus following the cessation of ACES as well as stimulation of different brain regions (core versus belt regions, lowversus high-frequency regions, ipsilateral versus contralateral hemispheres) using different stimulation parameters. Establishment of this animal model will allow in-depth investigations of the mechanisms underlying ACES-induced suppression of tinnitus, determination of the involved neural pathways, and targeted modulation of tinnitus neural correlates through ACES, as well as the development of noninvasive but high-stimulation-efficiency tinnitus prosthetic devices.

\section{ACKNOWLEDGMENTS}

The authors wish to thank Dr. Donald Godfrey and two anonymous reviewers for their valuable comments on the manuscript for its improvement. This work was supported by grant R21 DC010059-01 from the NIH/NIDCD.

\section{REFERENCES}

Ashton H, Reid K, Marsh R, Johnson I, Alter K, Griffiths T (2007) High FREQUENCY LOCALISED "HOT SPOTS" IN TEMPORAL LOBES OF PATIENTS WITH INTRACTABLE TINNITUS: A QUANTITATIVE ELECTROENCEPHALOGRAPHIC (QEEG) STUdy. Neurosci Lett 426:23-28

Axelsson A, Ringdahl A (1989) Tinnitus-a study of its prevalence AND CHARACTERISTICS. Br J Audiol 23:53-62

Bartels H, Staal MJ, Albers FW (2007) Tinnitus and neural PLASTICITY OF THE BRAIN. Otol Neurotol 28:178-184

Baumer T, Lange R, Liepert J, Weiller C, Siebner HR, Rothwell JC, Munchau A (2003) Repeated premotor rTMS leads to cumulative PLASTIC CHANGES OF MOTOR CORTEX EXCITABILITY IN HUMANS. Neuroimage 20:550-560

Bilak M, Kim J, Potashner SJ, Bohne BA, Morest DK (1997) New GROWTH OF AXONS IN THE COCHLEAR NUCLEUS OF ADULT CHINCHILLAS AFTER ACOUSTIC TRAUMA. Exp Neurol 147:256-268

Bjornsson CS, Oh SJ, Al Kofahi YA, Lim YJ, Smith KL, Turner JN, De S, Roysam B, Shain W, Kim SJ (2006) EFFeCts OF InSERTION CONDITIONS ON TISSUE STRAIN AND VASCULAR DAMAGE DURING NEUROPROSTHETIC DEVICE INSERTION. J Neural Eng 3:196-207

Bowen GP, Lin D, TAYLor MK, Ison JR (2003) Auditory Cortex Lesions IN THE RAT IMPAIR BOTH TEMPORAL ACUITY AND NOISE INCREMENT THRESHOLDS, REVEALING A COMMON NEURAL SUBSTRATE. Cereb CorteX $13: 815-822$

Braff DL, Geyer MA, Swerdlow NR (2001) Human studies of PREPULSE INHIBITION OF STARTLE: NORMAL SUBJECTS, PATIENT GROUPS, and pharmacological studies. Psychopharmacol Berl 156:234258

Campbell Le, Hughes M, Budd TW, Cooper G, Fulham WR, Karayanidis F, Hanlon MC, Stojanov W, Johnston P, Case V, Schall U (2007) Primary and secondary neural networks of AUDITORY PREPULSE INHIBITION: A FUNCTIONAL MAGNETIC RESONANCE IMAGING STUDY OF SENSORIMOTOR GATING OF THE HUMAN ACOUSTIC STARTLE RESPONSE. Eur J Neurosci 26:2327-2333

Chowdhury SA, Suga N (2000) Reorganization of the Frequency maP OF THE AUDITORY CORTEX EVOKED BY CORTICAL ELECTRICAL STIMULATION IN THE BIG BROWN BAT. J Neurophysiol 83:1856-1863

Clarkson C, Lopez DE, Merchán MA (2009) Long-term functional RECOVERY IN THE RAT AUDITORY SYSTEM AFTER UNILATERAL AUDITORY CORTEX ABLATION. Acta Otolaryngol 13:1-7 
Davis M, Gendelman DS, Tischler MD, Gendelman PM (1982) A PRIMARY ACOUSTIC STARTLE CIRCUIT: LESION AND STIMULATION STUDIES. J Neurosci 2:791-805

De Ridder D, De Mulder G, Walsh V, Muggleton N, Sunaert S, Moller A (2004) Magnetic and electrical stimulation of the auditory CORTEX FOR INTRACTABLE TINNITUS. Case report. J Neurosurg 100:560564

De Ridder D, Verstraeten E, Van der Kelen K, De Mulder G, Sunaert S, Verlooy J, van de Heyming P, Moller A (2005) Transcranial MAGNETIC STIMULATION FOR TINNITUS: INFLUENCE OF TINNITUS DURATION ON STIMULATION PARAMETER CHOICE AND MAXIMAL TINNITUS SUPPRESSION. Otol Neurotol 26:616-619

De Ridder D, De Mulder G, Verstraeten E, Van der Kelen K, Sunaert S, Smits M, Kovacs S, Verlooy J, van de Heyming P, Moller AR (2006) Primary and secondary auditory cortex stimulation fOR INTRACTABLE TINNITUS. ORL J Otorhinolaryngol Relat Spec 68:4854

De Ridder D, De Mulder G, Menovsky T, Sunaert S, Kovacs S (2007a) ELECTRICAL STIMULATION OF AUDITORY AND SOMATOSENSORY CORTICES FOR tReatMent of tinnitus and Pain. Prog Brain Res 166:377-388

De Ridder D, De Mulder G, Verstraeten E, Seidman M, Elisevich K, Sunaert S, Kovacs S, Van der Kelen K, Van de Heyming P, Moller A (2007в) AUditOry CORTEX STIMULATION FOR tinNITUS. Acta Neurochir Suppl 97:451-462

Dobie RA (2003) Depression And tinnitus. Otolaryngol Clin North Am 36:383-388

Doron NN, Ledoux Je, Semple MN (2002) Redefining the tonotopic CORE OF RAT AUDITORY CORTEX: PHYSIOLOGICAL EVIDENCE FOR A POSTERIOR FIELD. Eur J Neurosci 453:345-360

Eichhammer P, Kleinjung T, Landgrebe M, Hajak G, Langguth B (2007) TMS FOR TREATMENT OF CHRONIC TINNITUS: NEUROBIOLOGICAL EFFECTS. Prog Brain Res 166:369-375

Fenoy AJ, Severson Ma, Volkov IO, Brugge JF, Howard Ma III

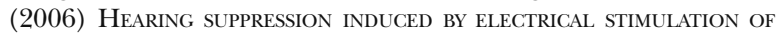
HUMAN AUDITORY CORTEX. Brain Res 1118:75-83

Folmer RL, Carroll JR, Rahim A, Shi Y, Hal MW (2006) Effects of REPETITIVE TRANSCRANIAL MAGNETIC STIMULATION (RTMS) ON CHRONIC TINNITUS. Acta Otolaryngol Suppl 556:96-101

Fregni F, Marcondes R, Boggio PS, Marcolin MA, Rigonatti SP, Sanchez TG, Nitsche MA, Pascual-Leone A (2006) Transient TINNITUS SUPPRESSION INDUCED BY REPETITIVE TRANSCRANIAL MAGNETIC STIMULATION AND TRANSCRANIAL DIRECT CURRENT STIMULATION. Eur J Neurol 13:996-1001

Friedland DR, Gaggl W, Runge-Samuelson C, Ulmer JL, Kopell BH (2007) Feasibility of aUditory CORTICAL stimulation FOR the TREATMENT OF TINNITUS. Otol Neurotol 28:1005-1012

Herbert H, Aschoff A, Ostwald J (1991) Topography of projections FROM THE AUDITORY CORTEX TO THE INFERIOR COLLICULUS IN THE RAT. J Comp Neurol 304:103-122

Higgins NC, Escabi MA, Rosen GD, Galaburda AM, Read HL (2008) SPECTRAL PROCESSING DEFICITS IN BELT AUDITORY CORTEX FOLLOWING EARLY POSTNATAL LESIONS OF SOMATOSENSORY CORTEX. Neuroscience 153:535-549

Howard MA III (2004) Tinnitus AND AUditory CORTEX. J Neurosurg 101:171-172

Ison JR, Castro J, Allen P, Virag TM, Walton JP (2002) The relative DETECTABILITY FOR MICE OF GAPS HAVING DIFFERENT RAMP DURATIONS AT THEIR ONSET AND OFFSET BOUNDARIES. J Acoust Soc Am 112:740-747

Jalinous R (1991) TeChNicAL AND PRACTiCAL ASPECTS OF MAGNETIC NERVE Stimulation. J Clin Neurophysiol 8:10-25

Kaltenbach JA, Zhang J (2007) Intense SOUND-INduced Plasticity in THE DORSAL COCHLEAR NUCLEUS OF RATS: EVIDENCE FOR CHOLINERGIC RECEPTOR UPREGULATION. Hear Res 226:232-243

Kaltenbach JA, Zhang J, Afman CE (2000) Plasticity of spontaneous NEURAL ACTIVITY IN THE DORSAL COCHLEAR NUCLEUS AFTER INTENSE SOUND EXPOSURE. Hear Res 147:282-292
Keliy JB, Saliy SL (1988) Organization of auditory cortex in the ALBINO RAT: BINAURAL RESPONSE PROPERTIES. J Neurophysiol 59:17561769

Kilgard MP, Merzenich MM (1999) Distributed representation of SPECTRAL AND TEMPORAL INFORMATION IN RAT PRIMARY AUDITORY CORTEX. Hear Res 134:16-28

Kilgard MP, Vazquez JL, Engineer ND, Pandya PK (2007) Experience DEPENDENT PLASTICITY ALTERS CORTICAL SYNCHRONIZATION. Hear Res 229:171-179

Komiya H, Eggermont JJ (2000) Spontaneous firing activity of CORTICAL NEURONS IN ADULT CATS WITH REORGANIZED TONOTOPIC MAP FOLLOWING PURE-TONE TRAUMA. Acta Otolaryngol 120:750-756

Langguth B, Hajak G, Kleinjung T, Pridmore S, Sand P, Eichhammer P (2006) Repetitive transcranial magnetic Stimulation and Chronic TINNITUS. Acta Otolaryngol Suppl 556:102-105

Langguth B, Kleinjung T, Marienhagen J, Binder H, Sand PG, Hajak G, EichHammer P (2007) Transcranial magnetic stimulation for THE TREATMENT OF TINNITUS: EFFECTS ON CORTICAL EXCITABILITY. BMC Neurosci 8:45

Langguth B, De RD, Dornhoffer JL, Eichhammer P, Folmer RL, Frank E, Fregni F, Gerloff C, Khedr E, Kleinjung T, Landgrebe M, Lee S, Lefaucheur JP, Londero A, Marcondes R, Moller AR, Pascual-Leone A, Plewnia C, Rossi S, Sanchez T, Sand P, Schlee W, Pysch D, Steffens T, van de Heyming P, Hajak G (2008) CONTROVERSY: DOES REPETITIVE TRANSCRANIAL MAGNETIC STIMULATION/ TRANSCRANIAL DIRECT CURRENT STIMULATION SHOW EFFICACY IN TREATING tinNitus patients? Brain Stimul 1:192-205

Leake PA, Hradek GT, Bonham BH, Snyder RL (2008) Topography of AUDITORY NERVE PROJECTIONS TO THE COCHLEAR NUCLEUS IN CATS AFTER NEONATAL DEAFNESS AND ELECTRICAL STIMULATION BY A COCHLEAR IMPLANT. J Assoc Res Otolaryngol 9:349-372

Lee Y, Lopez DE, Meloni EG, Davis M (1996) A primary acoustic STARTLE PATHWAY: OBLIGATORY ROLE OF COCHLEAR ROOT NEURONS AND THE NUCLEUS RETICULARIS PONTIS CAUDALIS. J Neurosci 16:3775-3789

Li X, Nahas Z, Kozel FA, Anderson B, Bohning DE, George MS (2004) Acute left prefrontal transcranial magnetic STimulation IN DEPRESSED PATIENTS IS ASSOCIATED WITH IMMEDIATELY INCREASED ACTIVITY IN PREFRONTAL CORTICAL AS WELL AS SUBCORTICAL REGIONS. Biol Psychiatry 55:882-890

Liberman MC, Gao WY (1995) Chronic cochlear De-efferentation AND SUSCEPTIBILITY TO PERMANENT ACOUSTIC INJURY. Hear Res 90:158168

Londero A, Langguth B, De Ridder D, Bonfils P, Lefaucheur JP (2006) Repetitive transcranial magnetic STIMUlation (RTMS): a NEW THERAPEUTIC APPROACH IN SUBJECTIVE TINNITUS? NEUROPHYSIOL CuIN 36:145-155

MaLdonado PE, Gerstein GL (1996) Neuronal assembiy dynamics in the RAT AUDITORY CORTEX DURING REORGANIZATION INDUCED BY INTRACORTICAL microstimUlation. Exp Brain Res 112:431-441

Martines F, Bentivegna D, Martines E, Sciacca V, Martinciglio G (2010) CHARACTERISTICS OF TINNITUS WITH OR WITHOUT HEARING LOSS: clinical observations in Sicilian tinnitus patients. Auris Nasus Larynx 37:685-693

McKenna L (2000) Tinnitus And Insomnia. In: Tyler RS (ed) Tinnitus handbook. Singular, San Diego, pp 59-84

Miller EJ, Saint Marie LR, Breier Mr, Swerdlow NR (2010) PATHWAYS From the veNTRAL hipPoCAMPUS AND CAUdAL AMYGDALA tO FOREBRAIN REGIONS THAT REGULATE SENSORIMOTOR GATING IN THE RAT. Neuroscience 165:601-611

Moore BC, Vinay, Sandhya (2010) The relationship between tinnitus PITCH AND THE EDGE FREQUENCY OF THE AUDIOGRAM IN INDIVIDUALS WITH HEARING IMPAIRMENT AND TONAL TINNITUS. Hear Res 261:51-56

Morest DK, Kim J, Potashner SJ, Bohne BA (1998) Long-term DEGENERATION IN THE COCHLEAR NERVE AND COCHLEAR NUCLEUS OF THE adult CHINChilla fOllowing acoustic overstimulation. Microsc Res Tech 41:205-216 
Muhlnickel W, Elbert T, Taub E, Flor H (1998) Reorganization of AUDITORY CORTEX IN tinNitus. Proc Natl Acad Sci USA 95:1034010343

Otto KJ, Rousche PJ, Kipke DR (2005A) Cortical microstimulation in AUDITORY CORTEX OF RAT ELICITS BEST-FREQUENCY DEPENDENT BEHAVIORS. J Neural Eng 2:42-51

Otto SR, Waring MD, Kuchta J (2005в) Neural response telemetry AND AUDITORY/NONAUDITORY SENSATIONS IN 15 RECIPIENTS OF AUDITORY BRAinstem implants. J Am Acad Audiol 16:219-227

Perlstein WM, Fiorito E, Simons RF, Graham FK (1993) Lead STIMULATION EFFECTS ON REFLEX BLINK, EXOGENOUS BRAIN POTENTIALS, AND Loudness Judgments. Psychophysiology 30:347-358

Plewnia C, Bartels M, Gerloff C (2003) Transient suppression of tinnitus by transcranial magnetic stimulation. Ann Neurol 53:263-266

Polley DB, Read HL, Storace DA, Merzenich MM (2007) MultiPARAMETRIC AUDITORY RECEPTIVE FIELD ORGANIZATION ACROSS FIVE CORTICAL FIELDS IN THE ALBINO RAT. J Neurophysiol 97:3621-3638

Ratnayake SA, Jayarajan V, Bartlett J (2009) Could an underlying HEARING LOSS BE A SIGNIFICANT FACTOR IN THE HANDICAP CAUSED BY tinNITUS? NOISE HEalth 11:156-160

Rousche PJ, Otto KJ, Reilly MP, Kipke DR (2003) Single electrode MICRO-STIMULATION OF RAT AUDITORY CORTEX: AN EVALUATION OF BEHAVIORAL PERFORMANCE. Hear Res 179:62-71

RUtKowski RG, WeINBerger NM (2005) EnCoding OF LEARNED IMPORTANCE OF SOUND BY MAGNITUDE OF REPRESENTATIONAL AREA IN PRIMARY AUDITORY CORTEX. Proc Natl Acad Sci USA 102:1366413669

Rutkowski RG, MiasnikovAA, Weinberger NM (2003) Characterisation OF MULTIPLE PHYSIOLOGICAL FIELDS WITHIN THE ANATOMICAL CORE OF RAT AUDITORY CORTEX. Hear Res 181:116-130

Schall U, Keysers C, Kast B (1999) Pharmacology of sensory gating IN THE ASCENding AUditory SYSTEM OF THE Pigeon (Columba Livia). Psychopharmacology (BerL). 145(3):273-282.

Schreiner CE, Cynader MS (1984) Basic functional organization of SECOND AUDITORY CORTICAL FIELD (AII) OF THE CAT. J Neurophysiol 51:1284-1305

Seidman MD, Ridder DD, Elisevich K, Bowyer SM, Darrat I, Dria J, Stach B, Jiang Q, Tepley N, Ewing J, Seidman M, Zhang J (2008) Direct electrical stimulation of Heschl's gyrus fOr tinNitus TREATMENT. Laryngoscope 118:491-500

Shore Se, Koehler S, Oldakowski M, Hughes LF, Syed S (2008) DORSAL COCHLEAR NUCLEUS RESPONSES TO SOMATOSENSORY STIMULATION ARE ENHANCED AFTER NOISE-INDUCED HEARING LOSS. Eur J Neurosci $27: 155-168$

Sobin C, KilerBrabeck K, Karayiorgou M (2005) Associations between PREPULSE INHIBITION AND EXECUTIVE VISUAL ATTENTION IN CHILDREN WITH THE 22Q11 DELETION SYNDROME. Mol Psychiatry 10:553-562

Sun W, Lu J, Stolzberg D, Gray L, Deng A, Lobarinas E, Salvi RJ (2009) Salicylate increases the gain of the CENTRAL auditory SYSTEM. Neuroscience 159:325-334
Swerdlow NR, Geyer MA, BrafF DL (2001) Neural circuit regulation OF PREPULSE INHIBITION OF STARTLE IN THE RAT: CURRENT KNOWLEDGE AND FUtURE CHALlenges. Psychopharmacol Berl 156:194-215

Syka J (2002) Plastic changes in the central auditory system after HEARING LOSS, RESTORATION OF FUNCTION, AND DURING LEARNING. Physiol Rev 82:601-636

Takahashi K, Nagai T, Kamei H, Maeda K, Matsuya T, Arai S, Mizoguchi H, Yoneda Y, Nabeshima T, Takuma K, Yamada $\mathrm{K}$ (2007) Neural circuits containing pallidotegmental GABAergic NEURONS ARE INVOLVED IN THE PREPULSE INHIBITION OF THE STARTLE REFLEX IN MICE. Biol Psychiatry 62:148-157

Talwar SK, Gerstein GL (2001) ReOrGanization IN AWAKE RAT AUditory CORTEX BY LOCAL MICROSTIMULATION AND ITS EFFECT ON FREQUENCY DISCRIMINATION BEHAVIOR. J Neurophysiol 86:1555-1572

Turner JG, Brozoski tJ, Bauer CA, Parrish JL, Myers K, Hughes LF, Caspary DM (2006) Gap Detection deficits in rats with tinnitus: a POTENTIAL NOVEL SCREENING TOOL. Behav Neurosci 120:188-195

Tyler RS (1993) Tinnitus DisAbILITY AND HANDicap Questionnaires. Sem Hear 14:377-383

Walton JP, Frisina RD, Ison JR, O’Neill WE (1997) Neurai CORRELATES OF BEHAVIORAL GAP DETECTION IN THE INFERIOR COLLICULUS OF THE young CBA mouse. J Comp Physiol A 181:161-176

Wang H, Brozoski TJ, Turner JG, Ling L, Parrish JL, Hughes LF, Caspary DM (2009) Plasticity at glycinergic synapses in DOrsal COCHLEAR NUCLEUS OF RATS WITH BEHAVIORAL EVIDENCE OF TINNITUS. Neuroscience 164:747-759

Witte RS, Rousche PJ, Kipke DR (2007) Fast wave propagation in AUDITORY CORTEX OF AN AWAKE CAT USING A CHRONIC MICROELECTRODE ARRAY. J Neural Eng 4:68-78

Yang G, Lobarinas E, Zhang L, Turner J, Stolzberg D, Salvi R, Sun W (2007) SALICYLATE INDUCED TINNITUS: BEHAVIORAL MEASURES AND NEURAL ACTIVITY IN AUDITORY CORTEX OF AWAKE RATS. Hear Res 226:244-253

Zhang JS, Kaltenbach JA (1998) Increases in SPontaneous activity in THE DORSAL COCHLEAR NUCLEUS OF THE RAT FOLLOWING EXPOSURE TO HIGH-INTENSITY SOUND. Neurosci Lett 250:197-200

Zhang JS, Zhang XG (2010) Electrical stimulation of the dorsal COCHLEAR NUCLEUS INDUCES HEARING IN RATS. Brain Res 1311:37-50

Zhang JS, Kaltenbach JA, Godfrey DA, Wang J (2006) Origin of HYPERACTIVITY IN THE HAMSTER DORSAL COCHLEAR NUCLEUS FOLLOWING INTENSE SOUND EXPOSURE. J Neurosci Res 84:819-831

Zhang JS, Guan ZL, Ramachandran V, Dunford J, Hoa M, Pace EMJ, Seidman M, Elisevich K, Bowyer S, Jiang Q (2008) Electricai MODULATION OF tinNITUS-RELATED ACtivity. Sem Hear 29:313-326

Zhang JS, Guan ZL, Zhang XG, Beydoun H, Zhang J, Seidman M, Elisevich K, Bowyer SM, Jiang Q, Moran J (2010) Cortical MODUlation of tinNitus and its NEURAL CORRELATES. N Z Med J 123:77-88

Zheng XY, Henderson D, Hu BH, Ding DL, McFadden SL (1997) The INFLUENCE OF THE COCHLEAR EFFERENT SYSTEM ON CHRONIC ACOUSTIC TRAUMA. Hear Res 107:147-159 